\title{
EANM guideline for ventilation/perfusion single-photon emission computed tomography (SPECT) for diagnosis of pulmonary embolism and beyond
}

\author{
Marika Bajc ${ }^{1}$ (D) Carl Schümichen ${ }^{2} \cdot$ Thomas Grüning $^{3}$ - Ari Lindqvist ${ }^{4} \cdot$ Pierre-Yves Le Roux $^{5} \cdot$ Adriano Alatri $^{6}$. \\ Ralf W. Bauer ${ }^{7,8} \cdot$ Mirza Dilic $^{9} \cdot$ Brian Neilly $^{10} \cdot$ Hein J. Verberne ${ }^{11} \cdot$ Roberto C. Delgado Bolton ${ }^{12} \cdot$ Bjorn Jonson $^{1}$
}

Received: 26 March 2019 / Accepted: 17 July 2019 / Published online: 13 August 2019

(C) The Author(s) 2019

\begin{abstract}
These guidelines update the previous EANM 2009 guidelines on the diagnosis of pulmonary embolism (PE). Relevant new aspects are related to (a) quantification of PE and other ventilation/perfusion defects; (b) follow-up of patients with PE; (c) chronic PE; and (d) description of additional pulmonary physiological changes leading to diagnoses of left ventricular heart failure (HF), chronic obstructive pulmonary disease (COPD) and pneumonia. The diagnosis of PE should be reported when a mismatch of one segment or two subsegments is found. For ventilation, Technegas or krypton gas is preferred over diethylene triamine pentaacetic acid (DTPA) in patients with COPD. Tomographic imaging with $\mathrm{V} / \mathrm{P}_{\mathrm{SPECT}}$ has higher sensitivity and specificity for PE compared with planar imaging. Absence of contraindications makes $\mathrm{V} / \mathrm{P}_{\mathrm{SPECT}}$ an essential method for the diagnosis of PE. When $\mathrm{V} / \mathrm{P}_{\mathrm{SPECT}}$ is combined with a low-dose $\mathrm{CT}$, the specificity of the test can be further improved, especially in patients with other lung diseases. Pitfalls in $\mathrm{V} / \mathrm{P}_{\mathrm{SPECT}}$ interpretation are discussed. In conclusion, $\mathrm{V} / \mathrm{P}_{\mathrm{SPECT}}$ is strongly recommended as it accurately establishes the diagnosis of PE even in the presence of diseases like COPD, HF and pneumonia and has no contraindications.
\end{abstract}

Keywords Pulmonary embolism · Ventilation-perfusion · SPECT · CTPA · V/P SPECT/CT · COPD · Left heart failure · Pneumonia $\cdot$ Chronic pulmonary embolism $\cdot$ Pulmonary hypertension

Abbreviations

AKI

COPD

Acute kidney injury

Chronic obstructive pulmonary disease
CTPA

CIN
Computed tomography pulmonary angiography

Contrast media-induced nephropathy

This article is part of the Topical Collection on Miscellanea

Marika Bajc

marika.bajc@med.lu.se

1 Department of Clinical Sciences, Clinical Physiology and Nuclear Medicine, University of Lund, Lund, Sweden

2 University of Rostock, Formerly Clinic for Nuclear Medicine, Rostock, Germany

3 Department of Nuclear Medicine, University Hospitals Plymouth, Plymouth, UK

4 Research Unit of Pulmonary Diseases, Clinical Research Institute, HUS Helsinki University Hospital, Helsinki, Finland

5 Department of Nuclear Medicine, University Hospital of Brest, Brest, France
6 Division of Angiology, Heart and Vessel Department, Lausanne University Hospital, Lausanne, Switzerland

7 RNS Gemeinschaftspraxis, Wiesbaden, Germany

8 Department of Diagnostic and Interventional Radiology, Goethe University Frankfurt (Main), Frankfurt, Germany

9 Clinic of Heart and Blood Vessel Disease, Clinical Center University of Sarajevo, Sarajevo, Bosnia and Herzegovina

10 Department of Nuclear Medicine, Royal Infirmary, Glasgow, UK

11 Department of Radiology and Nuclear Medicine, Amsterdam UMC, Location AMC, University of Amsterdam, Amsterdam, The Netherlands

12 Department of Diagnostic Imaging (Radiology) and Nuclear Medicine, University Hospital San Pedro and Centre for Biomedical Research of La Rioja (CIBIR), Logroño, La Rioja, Spain 


$\begin{array}{ll}\text { CTEPH } & \text { Chronic thromboembolic } \\ & \text { pulmonary hypertension } \\ \text { DTPA } & \text { Diethylene triamine pentaacetic acid } \\ \text { DVT } & \text { Deep venous thrombosis } \\ \text { EANM } & \text { European Association of Nuclear Medicine } \\ \text { ELISA } & \text { Enzyme-linked immunosorbent assay } \\ \text { ESC } & \text { European Society of Cardiology } \\ { }^{81 m} \mathrm{Kr} & \text { Radioactive krypton gas } \\ \text { MAA } & \text { Macroaggregated human albumin } \\ \text { NPV } & \text { Negative prediction value } \\ \text { OSEM } & \text { Ordered subset expectation maximisation } \\ \text { PE } & \text { Pulmonary embolism } \\ \text { PERC } & \text { Pulmonary embolism rule-out criteria } \\ \text { PIOPED } & \text { Prospective investigation of } \\ & \text { pulmonary embolism diagnosis } \\ \text { PPV } & \text { Positive predicitive value } \\ \text { SNMMI } & \text { The Society of Nuclear } \\ & \text { Medicine and Molecular Imaging } \\ \text { 99m Tc-DTPA } & 99 \mathrm{~m} \text { Tc-diethylen-tetraamino-pentaacetate } \\ \text { V/P } & \text { Ventilation and perfusion scan } \\ \text { V/PAR } & \text { with planar imaging } \\ \text { V/P } \text { SPECT } & \text { Ventilation and perfusion scan } \\ & \text { Ventilation and perfusion single-photon } \\ \text { VTE } & \text { emission tomography } \\ & \text { Venous thromboembolism }\end{array}$

Preamble The European Association of Nuclear Medicine (EANM) will periodically develop new guidelines for nuclear medicine practice to promote the science of nuclear medicine and to improve the quality of service to patients throughout Europe. Each practice guideline, representing an EANM policy statement, has undergone an extensive consensus and review process.

The EANM has written and approved these guidelines to promote the use of nuclear medicine procedures of high quality. These guidelines are intended to assist practitioners in providing appropriate nuclear medicine care for patients. They are not inflexible rules or requirements of practice and are not intended, nor should they be used, to establish a legal standard of care.

The ultimate judgment regarding the propriety of any specific procedure or course of action must be made by medical professionals considering the unique circumstances of each case. Thus, there is no implication that an approach differing from the guidelines is below the standard of care. On the contrary, a conscientious practitioner may responsibly adopt a course of action different from that set forth in the guidelines when, in the reasonable judgment of the practitioner, such course of action is indicated by the condition of the patient, limitations of available resources or advances in knowledge or technology subsequent to publication of the guidelines.

\section{Introduction}

These guidelines update the 2009 EANM guidelines on the diagnosis of pulmonary embolism (PE) $[1,2]$ for ventilation/ perfusion single-photon emission tomography (V/P $\left.\mathrm{P}_{\mathrm{SPECT}}\right)$. Since the previous EANM guidelines, little new data has emerged with regard to the technical aspects of V/P $\mathrm{P}$ SPECT. This document defines the role of $\mathrm{V} / \mathrm{P}_{\mathrm{SPECT}}$ in the diagnosis of PE and other cardiopulmonary diseases.

\section{Pulmonary embolism}

Nonthrombotic emboli may be septic, fat, amniotic fluid and air. In this document, PE refers to venous thromboembolism (VTE). PE is an important and treatable illness caused by migration of thrombi to the pulmonary circulation, commonly from the veins of the lower extremities (deep vein thrombosis: DVT). PE can cause death in the acute phase or later through chronic thromboembolic pulmonary hypertension.

Although independent VTE risk factors and predictors of VTE recurrence have been identified, and effective primary and secondary prophylaxis is available, the occurrence of VTE seems to be relatively constant, or even increasing [3]. Timely and accurate PE diagnosis is, therefore, essential.

\section{Natural history of PE}

The natural history of VTE has been extensively studied. Measurements of fibrinogen uptake were used by Kakkar et al. in the study evidencing that DVT developed in $30 \%$ of 132 patients undergoing surgery without prophylaxis [4]. In most patients, DVT developed in the calf veins, propagating to the proximal leg veins in $13 \%$. Forty-four percent of patients with proximal DVT developed PE. Evidence that DVT and PE are distinct manifestations of the same disease process, referred to as VTE, has been provided by observations showing that in the majority of patients with PE, DVT can be detected using sensitive methods. In patients with proven leg vein DVT, $40 \%$ have asymptomatic PE [5]. However, whereas VTE can present with one or both of these two manifestations, DVT and PE, epidemiological differences between both are important. Mortality is higher for PE than for DVT [6]. The International Cooperative Embolism Registry [7] aimed at determining baseline mortality rates and mechanisms of death reported a 3-month overall mortality rate of $15 \%$; the factors significantly associated with increased mortality being systolic arterial hypotension, congestive heart failure, cancer, tachypnoea, right ventricular hypokinesia, COPD and age > 70 years. Resolution of $\mathrm{PE}$ is variable. Evidence shows that a majority of patients have unresolved PE at 6 months from diagnosis [8]. Others report rapid resolution of a large PE within hours of the onset of heparin therapy [9]. Fredin and 
Arborelius evidenced complete restoration of lung perfusion in patients with PE within 1 week of diagnosis [10]. Based on this rapidly changing pattern of perfusion in PE, Coakley recommended that imaging tests for PE diagnosis should be carried out as soon as possible, preferably within $24 \mathrm{~h}$ after onset of symptoms [11].

\section{Epidemiology}

Venous thromboembolism is a major cause of morbidity, mortality and hospitalisation [3, 12-14]. A model based on data from 6 European countries with a combined population of 310 million found approximately 466,000 cases of DVT and 296,000 cases of PE in 2004. These resulted in approximately 370,000 deaths, of which $7 \%$ were thought to be from diagnosed and treated VTE, 34\% from sudden fatal PE and 59\% from PE following undiagnosed VTE [3]. Incidence for DVT and PE increases with age. VTE is rare prior to late adolescence $[12,15,16]$.

One-third of PE episodes occur without any known risk factor and are classified as 'unprovoked' [17]. The remaining 'provoked' PE episodes are secondary to a risk factor that may be temporary (e.g. surgery, trauma, immobilisation, pregnancy, oral contraceptive or hormone replacement therapy) or persistent (e.g. cancer or inherited thrombophilia) [12, 18, 19]. About $20 \%$ of all VTEs are cancer-related [20]. Surgery and immobilisation each account for $15 \%$ of cases [21]. Not infrequently, PE is without clinical manifestations [22].

The most frequent inherited risk factors are factor $\mathrm{V}$ and prothrombin (factor II) gene mutations. These have a European prevalence of 3-7\% and 1-2\%, respectively [23].

Following a PE, about one-third of patients show persistent pulmonary perfusion defects [24-26]. Chronic thromboembolic pulmonary hypertension (CTEPH) is the principal long-term complication of $\mathrm{PE}$ with an incidence of $0.1-4 \%$ [27].

PE frequently recurs, usually after discontinuation of anticoagulation $(13 \%$ at 1 year, $23 \%$ at 5 years and $30 \%$ at 10 years) [12]. Recurrence rate is higher after unprovoked VTE than after provoked VTE and higher after multiple episodes compared with a single event [12].

\section{Pathophysiology}

When unperfused regions are ventilated, there is an increase in the dead space [28]. This is one of the reasons for dyspnoea. Hypoxia, frequently present in major PE, is caused by several mechanisms. The emboli occluding pulmonary end arteries alter the local equilibrium and, therefore, can lead to haemorrhage, atelectasis, pleural effusion and pleuritic pain. The lung has no pain fibres; thus, pain in PE is a symptom consequence of the involvement of the parietal pleura.
Moreover, there is also increased pulmonary vascular resistance that can produce right ventricular strain and failure, electromechanical dissociation, hypotension, syncope and sudden death. Pressure increase in the right atrium may lead to right-to-left shunt through a patent foramen ovale, contributing to hypoxaemia. The shunt can also produce paradoxical emboli, resulting in infarctions from venous thrombi in the systemic circulation, commonly the brain [29-31].

\section{Clinical presentation}

The clinical signs of PE range from asymptomatic to sudden death [12, 22]. Most patients with PE have symptoms including dyspnoea, tachypnoea, chest pain (pleuritic or retrosternal), cough, fever, haemoptysis, syncope, unilateral leg pain or swelling, palpitations, tachycardia or dizziness due to hypotension $[32,33]$. Arterial hypotension and shock are rare signs indicating central massive PE and/or a severely reduced haemodynamic reserve, and these clinical signs and symptoms indicate high-risk PE. It is associated with particularly high early mortality [31]. In the case of central PE, chest pain may have the characteristics of angina, probably because of right ventricular ischemia, and poses the problem of differentiating PE from acute coronary syndrome and aortic dissection [31].

The clinical features of PE are also common in patients without $\mathrm{PE}[32,33]$, and the prevalence of $\mathrm{PE}$ in patients with clinically suspected VTE is only about $20 \%$ [34, 35]. Therefore, there is a risk that an undue number of patients might receive an unnecessary imaging procedure. Thus, assessments of clinical PE probability and D-dimer testing are important steps in clinical practice to guide decisions about who should be referred for imaging $[31,36]$. The chest radiograph is useful for alternative diagnoses such as pneumothorax, pneumonia, COPD, lung cancer or pulmonary fibrosis.

\section{Assessment of pretest clinical probability}

Clinical probability for PE can be assessed empirically by clinical judgement (holistically) or by clinical prediction rules, foremost Wells' and the revised Geneva scores [37, 38], which have been adequately validated [34, 35, 39] and recommended by EANM, the Society of Nuclear Medicine and Molecular Imaging and the European Society of Cardiology (ESC) [31, 40]. For both scores, simplified and validated versions are available [39, 41-44]. Usually, patients are clinically stratified into two or three risk categories: unlikely/likely and low/intermediate/high with increasing prevalence of PE [45].

\section{D-dimer testing}

Plasma D-dimer (a breakdown product of fibrin clot) is not only regularly elevated in patients with venous 
thromboembolism but also in myocardial infarction, stroke, infection, inflammation, cancer and pregnancy. The specificity of D-dimer is, therefore, low, and a positive D-dimer test does not confirm PE. However, the D-dimer test is very sensitive. Therefore, when the D-dimer is below a predefined cutoff value (i.e. $<500 \mu \mathrm{g} / \mathrm{L}$ with correction for age), it can be used to exclude PE in patients with either low to intermediate or unlikely clinical probability $[31,46]$. However, in old and persistent PE, D-dimer can be negative. In patients with a high or likely clinical probability, the D-dimer has no discriminating power and should not be measured [47].

In a recent randomised clinical trial including 1916 patients with suspected PE, considered by clinical judgement (holistically) to be at very low risk for PE, the use of the pulmonary embolism rule-out criteria (PERC) safely excluded PE [48]. The PERC strategy may reduce the number of D-dimer tests in patients with very low clinical probability of PE [48], although caution is advised in using the PERC rule [49].

\section{Imaging tests}

In patients with a low or intermediate clinical probability but positive D-dimer, and in patients with a high or likely clinical probability, lung imaging is required. The two mainly used imaging modalities are as follows:

- $\mathrm{V} / \mathrm{P}$ imaging with SPECT $\left(\mathrm{V} / \mathrm{P}_{\mathrm{SPECT}}\right)$ or in rare situations planar scintigraphy $\left(\mathrm{V} / \mathrm{P}_{\text {planar }}\right)$. Occasionally, perfusiononly lung scanning is performed. $\mathrm{V} / \mathrm{P}_{\text {SPECT }}$ may also be combined with low-dose computed tomography (CT), $\mathrm{V} / \mathrm{P}_{\mathrm{SPECT} / \mathrm{CT}}$

- Computed tomography of the pulmonary arteries (CTPA)
Invasive pulmonary angiography is no longer regarded as the gold standard for the diagnosis of PE because of its limited sensitivity and specificity and wide interobserver variability [50].

Transthoracic echocardiography was discussed in the former guidelines in haemodynamically unstable patients $[1,2]$. In a recent review, the need for further research on this topic is underlined [51].

\section{Basic principles of PE diagnosis}

PE leads to loss of perfusion to the area corresponding to the volume supplied by the occluded end artery that may be a whole lung, a lobe, a lung segment or a subsegment. In general, the bronchial circulation maintains viability of the embolised volume, and ventilation remains largely intact. Accordingly, $\mathrm{V} / \mathrm{P}_{\mathrm{SPECT}}$ exploits the unique pulmonary arterial segmental anatomy. Figure 1 presents a segmental map, and a case with PE is shown in Fig. 2.

$\mathrm{PE}$ is in general an acute disease that should be diagnosed and treated without delay. $\mathrm{V} / \mathrm{P}_{\mathrm{SPECT}}$ should, therefore, be performed according to a 1-day protocol. $\mathrm{V} / \mathrm{P}_{\text {planar }}$ should only be used when a patient for any reason cannot be examined by $\mathrm{V} / \mathrm{P}_{\mathrm{SPECT}}$.

\section{Radiopharmaceuticals for V/P SPECT $_{\text {S }}$}

\section{Ventilation}

Ventilation can be evaluated with the ${ }^{99 \mathrm{~m}} \mathrm{Tc}$-labelled aerosols, DTPA and Technegas ${ }^{\circledR}$, or krypton gas $\left({ }^{81 \mathrm{~m}} \mathrm{Kr}\right)$ (Table 1).
Fig. 1 Segmental map of the two lungs in four coronal slices and two sagittal slices for each lung. A bronchopulmonary segment is conical with its apex towards the hilum and its base projected onto the pleural surface. Thrombi occluding pulmonary arteries, therefore, produce characteristic lobar, segmental or subsegmental peripheral wedge-shaped defects with the base reaching the pleural surface
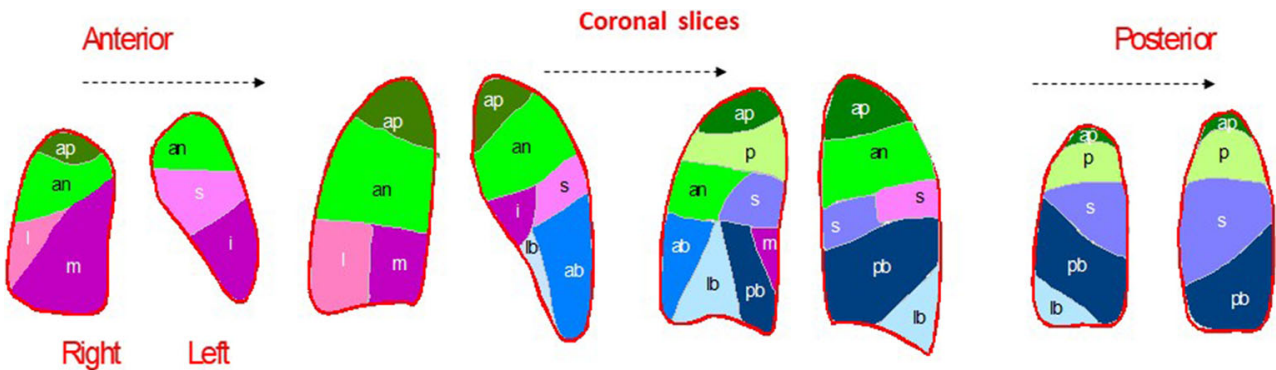

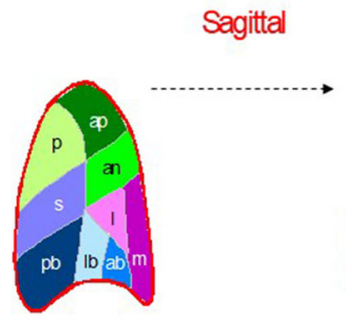

Right

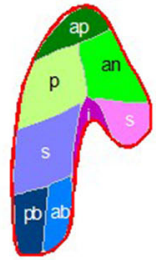

Left 
Fig. 2 Coronal slices in a patient with PE. Multiple bilateral segmental perfusion defects (red arrows) in areas with normal ventilation. These are delineated on V/P quotient images which facilitate interpretation

\section{CORONAL}

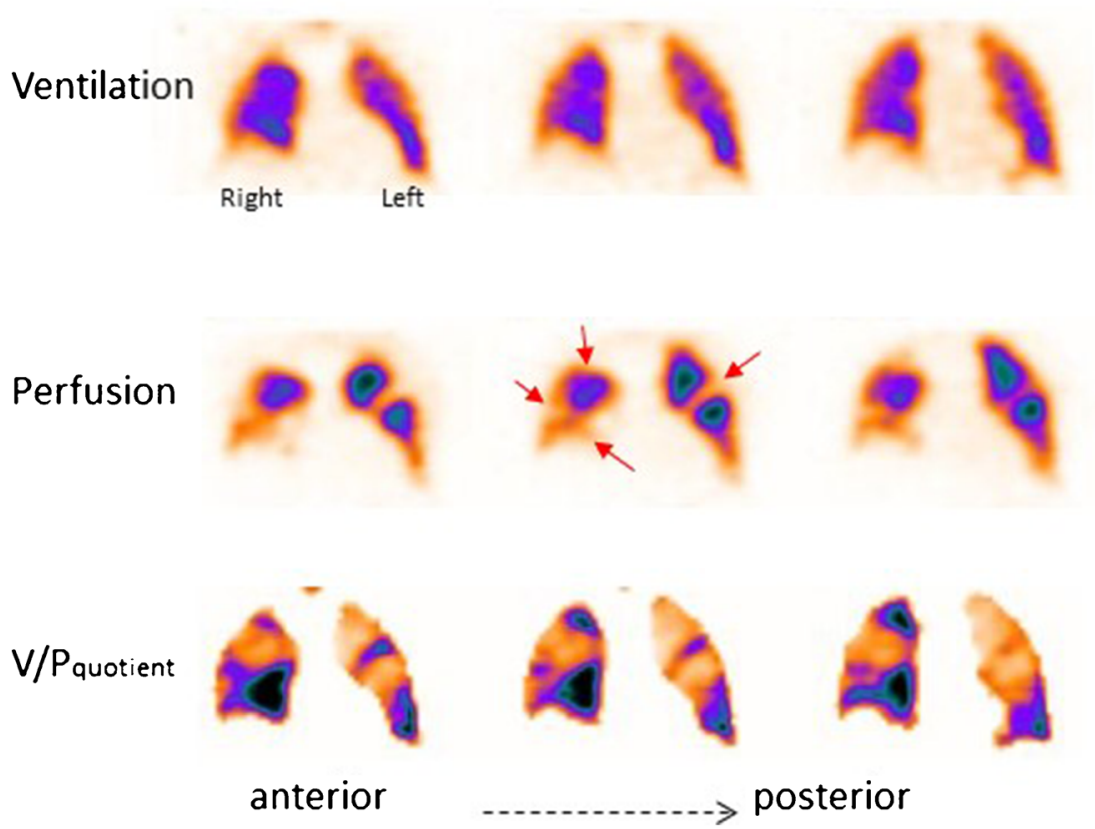

${ }^{99 \mathrm{~m}} \mathrm{Tc}-\mathrm{DTPA}\left({ }^{99 \mathrm{~m}} \mathrm{Tc}\right.$-diethylen-tetraamino-pentaacetate) is aerosolised from a water solution with a particle size of 1.2$2 \mu \mathrm{m} .{ }^{99 \mathrm{~m}} \mathrm{Tc}-\mathrm{DTPA}$ allows studies of alveolo-capillary permeability [58].

Technegas $^{\circledR}$ is an aerosol of ${ }^{99 \mathrm{~m}}$ Tc-labelled solid graphite hydrophobic particles, with a diameter of about $0.005-0.2 \mu \mathrm{m}$ [59]. The particles tend to grow by aggregation and should, therefore, be used within $10 \mathrm{~min}$ after generation [60]. The particle size is so small that the aerosol behaves nearly like a gas until it arrives at the periphery of the lung where the particles are deposited in bronchioli and alveoli, mostly by diffusion. Technegas ${ }^{\mathbb{R}}$ greatly reduces the problem of central deposition often encountered with ${ }^{99 \mathrm{~m}} \mathrm{Tc}-\mathrm{DTPA}$. Technegas ${ }^{\circledR}$ facilitates interpretation, particularly in COPD [58]. Hotspots are nevertheless seen in patients with severe airway obstruction. The penetration index for Technegas ${ }^{\circledR}$ may be used for grading of COPD severity [61, 62].

Krypton gas $\left({ }^{81 \mathrm{~m}} \mathrm{Kr}\right)$ is an inert radioactive gas delivered from an ${ }^{81} \mathrm{Rb} /{ }^{81 \mathrm{~m}} \mathrm{Kr}$ generator. ${ }^{81 \mathrm{~m}} \mathrm{Kr}$ has a half-life of $13 \mathrm{~s}$. ${ }^{81 \mathrm{~m}} \mathrm{Kr}$ is inhaled until it reaches a steady-state activity in the alveoli and then continuously during the whole imaging procedure. Due to the higher gamma energy (190 keV) of ${ }^{81 \mathrm{~m}} \mathrm{Kr}$ compared with ${ }^{99 \mathrm{~m}} \mathrm{Tc}(140 \mathrm{keV})$, ventilation and perfusion images can be acquired simultaneously. Because elimination of ${ }^{81 \mathrm{~m}} \mathrm{Kr}$ from the alveoli is largely due to decay of the isotope rather than by expiration, regional activity at steady state accurately represents regional ventilation. In COPD, the inhalation time to reach steady state may, however, be too long to reach steady state. As the half-life of ${ }^{81} \mathrm{Rb}$ is only $4.6 \mathrm{~h}$, the need for daily delivery of the expensive cyclotron-produced generator limits the clinical use of ${ }^{81 \mathrm{~m}} \mathrm{Kr}$.

\section{Perfusion}

For perfusion scintigraphy, intravenously injected macroaggregates of ${ }^{99 \mathrm{~m}} \mathrm{Tc}$-labelled human albumin (MAA) with a diameter of $15-100 \mu \mathrm{m}$ are nearly universally used. Intravenous injection of MAA leads to microembolisation of pulmonary precapillary arterioles and capillaries. Whilst
Table 1 Dosimetry of radiopharmaceuticals used for $\mathrm{V} / \mathrm{P}_{\mathrm{SPECT}}$

\begin{tabular}{llll}
\hline Radiopharmaceutical & $\begin{array}{l}\text { Administered activity } \\
(\mathrm{MBq})\end{array}$ & $\begin{array}{l}\text { Critical organ } \\
(\mathrm{mGy} / \mathrm{MBq})\end{array}$ & $\begin{array}{l}\text { Effective dose } \\
(\mathrm{mSv} / \mathrm{MBq})\end{array}$ \\
\hline${ }^{99 \mathrm{~m}} \mathrm{Tc}-\mathrm{MAA}[52]$ & $40-120$ & 0.067 lungs & 0.017 \\
${ }^{99 \mathrm{~m}} \mathrm{Tc}-\mathrm{DTPA}[53]$ & $20-30$ & 0.047 bladder & 0.007 \\
${ }^{99 \mathrm{~m}} \mathrm{Tc}-$ Technegas [54] & $20-30$ & 0.11 lungs & 0.015 \\
${ }^{81 \mathrm{~m}} \mathrm{Kr}$ [55] & $40-400$ & 0.0068 lungs & 0.0007 \\
\hline
\end{tabular}

The biological half-life of ${ }^{99 \mathrm{~m}}$ Tc-DTPA is 55-108 min [56] and of ${ }^{99 \mathrm{~m}}$ Tc-Technegas $135 \mathrm{~h}$ [57] 
60,000 particles may suffice to reflect regional perfusion [63], about 400,000 labelled particles are usually injected. This leads to obstruction of a very small fraction of pulmonary vessels. Injection of no more than 100,000-200,000 particles is recommended for patients with known pulmonary hypertension, right-to-left heart shunt, pneumonectomy or after single lung transplantation. In infants and children, the number of particles is recommended to be further reduced according to weight [64].

Because of religious beliefs, it may be advisable to inform patients that MAA is a blood product.

\section{Quality control and injection practice}

As radiochemical purity varies, supernatant activity should be determined. As particles tend to settle, the vial should be shaken before use. Withdrawal of blood into the syringe should be avoided, as this will cause aggregation of MAA particles resulting in artefactual hotspots. The MAA suspension should be injected over 30 s, i.e. over several breaths, to promote distribution reflecting regional pulmonary perfusion. Patients should be in a supine position during inhalation, intravenous injection and during scanning.

\section{Imaging protocols}

Using aerosols, imaging starts with the ventilation scan, immediately followed by the perfusion scan, according to principles based on an extensive analysis serving to optimise radioactivity doses, the relationship between activities and scanning time for ventilation and perfusion, type of collimator, number of rotational steps, matrix size and image reconstruction algorithm [65] (Table 2). Activities of 25-30 MBq and 140-160 MBq are sufficient for ventilation and perfusion studies, respectively, with a general-purpose collimator, $64 \times 64$ matrix and 60-64 rotational steps of a dual head gamma-camera, i.e. $120-128$ projections [65,
66]. Time per projection should be $10 \mathrm{~s}$ for ventilation and $5 \mathrm{~s}$ for perfusion studies.

This principle leads to the lowest radiation exposure consistent with adequate image quality and, therefore, is in accordance with good medical practice. It is applied in commercially available software and hardware systems and is recommended in these guidelines. Deviations from these validated standards require complementary documentation. The use of low-energy high-resolution (LEHR) collimators would require either longer acquisition times or higher activities.

Iterative reconstruction is essential, e.g. ordered subset expectation maximisation (OSEM). For comparison between ventilation and perfusion including triangulation, the patient must be in the same position for the whole image acquisition.

Perfusion-only scintigraphy is recommended as a first step during the first 3 months of pregnancy and in the case of suspected massive PE (see below).

\section{Image presentation}

Standard software allows image presentation in coronal, sagittal and transverse projections as well as the presentation of rotating 3D images (Segami, Hermes, GE and others). Ventilation/perfusion quotient images may be derived from the primary images $[65,66]$. Ventilation counts are normalised to perfusion counts before V/P quotient images are calculated. V/P quotient images facilitate diagnosis and quantification of PE extension. As attenuation is the same for ventilation and perfusion, V/P images do not require attenuation correction.

For quality control and fast orientation, an overview of ventilation and perfusion in coronal and sagittal slices is useful. For identification of matched and mismatched ventilation and perfusion changes and particularly for calculation of V/P quotient images, it is essential that ventilation and perfusion images are carefully aligned to each other. An example is shown in Fig. 2 of a patient with PE and multiple segmental perfusion defects, well delineated on V/P quotient images. This is facilitated by the one-session protocol

Table 2 Summary of ventilation/perfusion protocol for $\mathrm{V} / \mathrm{P}_{\text {SPECT }}$. Patients should be in a supine position during inhalation, intravenous injection and during scanning

\begin{tabular}{lll}
\hline & Ventilation & Perfusion \\
\hline Administration & Inhalation & Intravenous injection \\
Radiopharmaceutical administered activity & Technegas $^{\circledR}$ or DTPA $25-30 \mathrm{MBq}$ to reach the lung & $99 \mathrm{~m}$ Tc-MAA $120-160 \mathrm{MBq}$ \\
Particle size & $0.005-0.2 \mu \mathrm{m}$ or $1.2-2 \mu \mathrm{m}$ & $15-100 \mu \mathrm{m}$ \\
Time of imaging & $\approx 11 \mathrm{~min}$ & $\approx 5 \mathrm{~min}$ \\
Acquisition protocol & General purpose collimator: $64 \times 64$ matrix, 60-64 steps & \\
Reconstruction & $\quad$ for each head, 5 s/step (V) 10 s/step (P) [65, 66] & \\
\hline
\end{tabular}


with the patient in an unchanged position. Although helpful, V/P quotient images are not a prerequisite for high quality $\mathrm{V} / \mathrm{P}_{\mathrm{SPECT}}$. The option to triangulate between coronal, sagittal and transverse slices is valuable.

\section{Interpretation and reporting of findings}

\section{Ventilation/perfusion patterns}

For $\mathrm{V} / \mathrm{P}_{\mathrm{SPECT}}$, interpretation criteria are as important as the imaging technique itself. Studies based on probabilistic reporting of planar imaging (PIOPED I) show high rates of nondiagnostic reports. In contrast, $\mathrm{V} / \mathrm{P}_{\mathrm{SPECT}}$ with holistic interpretation (Table 3 ) is associated with very low rates of nondiagnostic reports and allows a diagnostic conclusion that is binary with respect to PE. All ventilation and perfusion patterns as well as the extent of defects should be described. A few patients might show widespread V/P abnormalities not specific for any disease.

\section{Criteria for acute pulmonary embolism}

The recommended basic criteria for reading V/P scintigraphy are the following:

PE:

- V/P mismatch of at least one segment or two subsegments in keeping with the pulmonary vascular anatomy (wedge-shaped defects with the base projecting to the lung periphery).

No PE:

- Normal perfusion pattern in keeping with the anatomic boundaries of the lungs.

- Matched or reversed-mismatched V/P defects of any size, shape or number in the absence of mismatch.

- Mismatch that does not follow a lobar, segmental or subsegmental pattern.

Nondiagnostic for PE:

- Widespread V/P abnormalities not typical of specific diseases.

Table 3 Semiology of lung ventilation/perfusion pathology with $\mathrm{V} / \mathrm{P}_{\text {SPECT. }}$ Interpretation and differential diagnosis

\begin{tabular}{|c|c|c|c|c|c|}
\hline \multicolumn{3}{|l|}{ Semiology } & \multirow[t]{2}{*}{ Diagnosis } & \multirow{2}{*}{$\begin{array}{l}\text { Probability that the } \\
\text { semiologic pattern is } \\
\text { diagnostic }\end{array}$} & \multirow[t]{2}{*}{ Level of evidence } \\
\hline Pattern & Distribution & Area & & & \\
\hline \multirow[t]{8}{*}{ Mismatch } & \multirow[t]{3}{*}{ Segmental } & 1 segment & $\mathrm{PE}^{*}$ & Very high & \\
\hline & & $\geq 2$ subsegments & $\mathrm{PE}^{*}$ & Very high & \\
\hline & & $\leq 1$ subsegment & Non-PE & High & \\
\hline & \multirow{3}{*}{$\begin{array}{l}\text { Total lung } \\
\text { unperfused }\end{array}$} & \multirow[t]{3}{*}{ Total lung } & Tumour ${ }^{\#}$ & High & \\
\hline & & & Abscess ${ }^{\#}$ & High & \\
\hline & & & Massive PE & Very low (rare) & Very rare condition \\
\hline & \multirow[t]{2}{*}{ Nonsegmental } & $\begin{array}{l}\text { Systematically antigravitational } \\
\text { redistribution }\end{array}$ & Heart failure & High & \\
\hline & & Irregular & Vasculitis & Very low (rare) & $\begin{array}{l}\text { Very rare condition, expert } \\
\text { opinion }\end{array}$ \\
\hline \multirow[t]{4}{*}{ Match } & \multirow{4}{*}{$\begin{array}{l}\text { Segments or } \\
\text { lobules }\end{array}$} & \multirow[t]{3}{*}{ No stripe sign } & Tumour & \multirow{3}{*}{$\begin{array}{l}\text { Depends on } \\
\text { clinical context }\end{array}$} & \\
\hline & & & Atelectasia & & \\
\hline & & & Empyema & & \\
\hline & & Stripe sign & $\begin{array}{l}\text { Pneumonia } \\
\text { evolutioned stage }\end{array}$ & High & \\
\hline \multirow[t]{2}{*}{$\begin{array}{l}\text { Reverse } \\
\quad \text { mismatch }^{\S}\end{array}$} & \multirow[t]{2}{*}{$\begin{array}{l}\text { Segments or } \\
\text { lobules }\end{array}$} & Stripe sign & $\begin{array}{l}\text { Pneumonia initial } \\
\text { stage }\end{array}$ & High & \\
\hline & & No stripe sign & COPD & High & \\
\hline
\end{tabular}

*Even in the presence of concomitant pathologies

\# Recommend CTPA

$\S$ More reduction of ventilation than perfusion 
As proposed in the 2009 EANM guidelines, the diagnostic cut-off to consider a $\mathrm{V} / \mathrm{P}_{\text {SPECT }}$ positive for PE should be 1 segmental or 2 subsegmental mismatched defects. This principle is further supported [67], and its safety was confirmed in large studies [67-69]. A single subsegmental mismatched perfusion defect should be reported but does not fulfil diagnostic criteria for PE. In some cases, PE may be found on CTPA in such patients, but clinical significance is not documented. Pulmonary arteries and capillary beds uniquely possess fibrinolytic properties that both trap and lyse small subsegmental clots, suggesting that small PEs are a common physiological phenomenon.

Recommendations from the ESC suggest an individualised approach; patients can be managed conservatively if the presence of deep vein thrombosis has been excluded [56]. Patients with a Wells score $>4$ have a 4 -fold increased risk of adverse outcome with one or multiple emboli in subsegmental arteries [70].

Applying these principles of interpretation, recent $\mathrm{V} / \mathrm{P}_{\text {SPECT }}$ studies amounting to over 5000 cases report a negative predictive value of $97-99 \%$, sensitivities of $96-99 \%$ and specificities of $96-98 \%$ for PE diagnosis. Rates of nondiagnostic findings were $1-4 \%[61,68,69,71-78]$.

\section{Pitfalls in the interpretation of V/PSPECT}

As with any diagnostic test, it is vital that the reporting physician has the knowledge of a number of sources of error. These include the following:

- Technical artefacts may arise from preinjection handling of the ${ }^{99 \mathrm{~m}} \mathrm{Tc}-\mathrm{MAA}$. The withdrawal of blood into the syringe that contains the solution of ${ }^{99 \mathrm{~m}} \mathrm{Tc}-\mathrm{MAA}$ can cause the aggregation of particles that can produce hotspots in the images. A similar consequence can appear from failure to resuspend ${ }^{99 \mathrm{~m}} \mathrm{Tc}-\mathrm{MAA}$ particles before the administration.

- Planar imaging may underestimate the presence or extent of perfusion abnormalities because of normal perfusion masking embolised regions, also known as the shine through of normal areas. This problem is eliminated by $\mathrm{V} / \mathrm{P}_{\text {SPECT }}$.

- Technegas ${ }^{\circledR}$ is preferred over liquid aerosols in patients with COPD. Moreover, in rare patients with emphysema, Technegas ${ }^{\circledR}$ particles are trapped in bullae in which perfusion is absent. This causes a pattern that may be mistaken for a mismatch [76, 79].

- In rare cases, vasculitis and congenital vascular anomalies may lead to segmental/lobar mismatches.

- Mismatched perfusion defects without a clear segmental character may be seen in older, partly resolved PE, but not related to acute PE. These nonsegmental mismatched defects are observed in several lung disorders including lung cancer, mediastinal lymphadenopathy, postradiation pneumonitis/fibrosis and heart failure. $\mathrm{V} / \mathrm{P}_{\mathrm{SPECT}}$ facilitates the identification of segmental perfusion defects, which are particularly well visualised when using rotating 3D volumetric images.

- Unilateral absence of perfusion in a whole lung with preserved ventilation and without any V/P mismatch in the other lung is generally not due to PE [80, 81]. In such cases, chest CT may reveal the presence of other pathologies such as tumour, aortic dissection, other mediastinal processes or congenital pulmonary vascular abnormalities.

- The 'rind' artefact seen in ventilation SPECT represents a band of increased activity along the posterior (dependent) portion of the lung. This is probably produced by dynamic changes in the lung volume during the acquisition $[57,82]$.

- Fissure artefacts are a common finding along the line of the oblique fissure, especially in perfusion SPECT. It may produce a nonsegmental mismatch [57].

\section{Additional considerations}

\section{Quantification of PE extent}

The extent of PE is an independent risk factor for PE recurrence [83-85]. Quantification of PE may be useful for the management of patients with acute PE [86]. V/P $\mathrm{P}_{\mathrm{SPECT}}$ is particularly suitable for quantification. The number of segments and subsegments indicating mismatch typical of PE can be counted and expressed as a percentage of the total lung parenchyma. However, as the volume of each segment and subsegment is different, this calculation is approximate providing a semiquantification of the percentage of the total lung parenchyma affected. Furthermore, areas with ventilation abnormalities can be recognised allowing for the assessment of the degree of total lung function affected. In haemodynamically stable patients with $\mathrm{PE}$, outpatient management is safe provided that the embolic burden, quantified using $\mathrm{V} / \mathrm{P}_{\mathrm{SPECT}}$, is included in the treatment decision algorithm [86].

\section{Follow-up}

The natural history of PE is still not well known. Alternative strategies for PE therapy should be studied, regarding therapy duration and choice of drugs in different categories of patients. The issue of small emboli is particularly relevant, as the need for treatment is not properly supported by evidence. Figure 3 presents a patient with untreated small PE who developed chronic PE after 3 months of follow-up.

Follow-up of PE using imaging is essential to:

- Assess therapy effect

- Differentiate between new and old PE when there is a suspicion of PE recurrence

- Explain physical incapacity after PE 
Fig. 3 Sagittal slices of both lungs in a patient with small PE (red arrows), initially (not treated) and 3 months later. On follow-up, the progression of perfusion defects as well as deterioration in the ventilation (blue arrow in the left lung) can be seen clearly. The patient also developed pneumonia
Initially

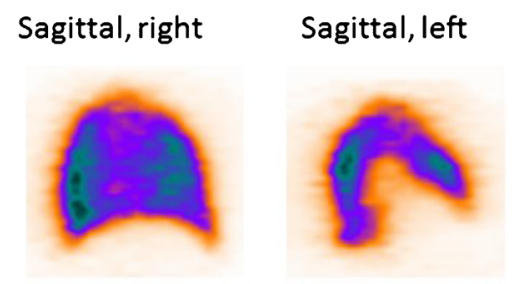

Ventilation

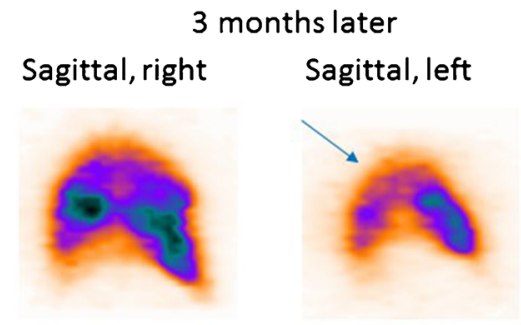

Perfusion
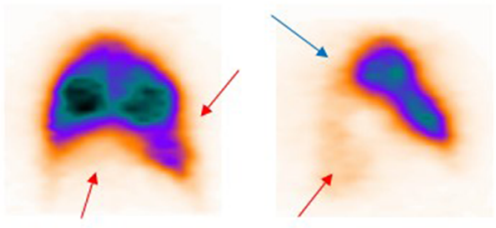

V/P quotient
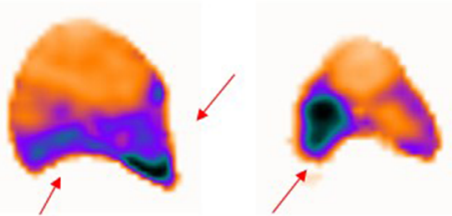

Some patients tend to develop recurrent episodes of PE. Figure 4 presents a patient with recurrent PE, shown by follow-up scans. Without both initial and follow-up images, it is often impossible to differentiate between old and new PE. The risks in patients treated with thrombolysis for massive PE include not only bleeding but also those related to unresolved PE. Immediate imaging control provides objective information on the need for repeated thrombolysis.
Symptomatic patients with small emboli are diagnosed with sensitive methods, particularly $\mathrm{V} / \mathrm{P}_{\mathrm{SPECT}}$. Figure 5 presents a case with PE in the middle lobe and pneumonia in the posterior right lung which could not have been identified without SPECT and ventilation images.

The natural history and the efficacy of treatment in this group of patients is rather unknown. Thus, follow-up is indicated to individualise therapy [87-89].
Fig. 4 Coronal slices in a patient with recurrent PE (red arrows), initially referred after a diagnosis of pulmonary hypertension. PE was not identified on CT. The first follow-up scan shows new perfusion defects that occurred after stopping therapy, and the final follow-up identifies improving perfusion after 4 months of treatment

\section{CORONAL}

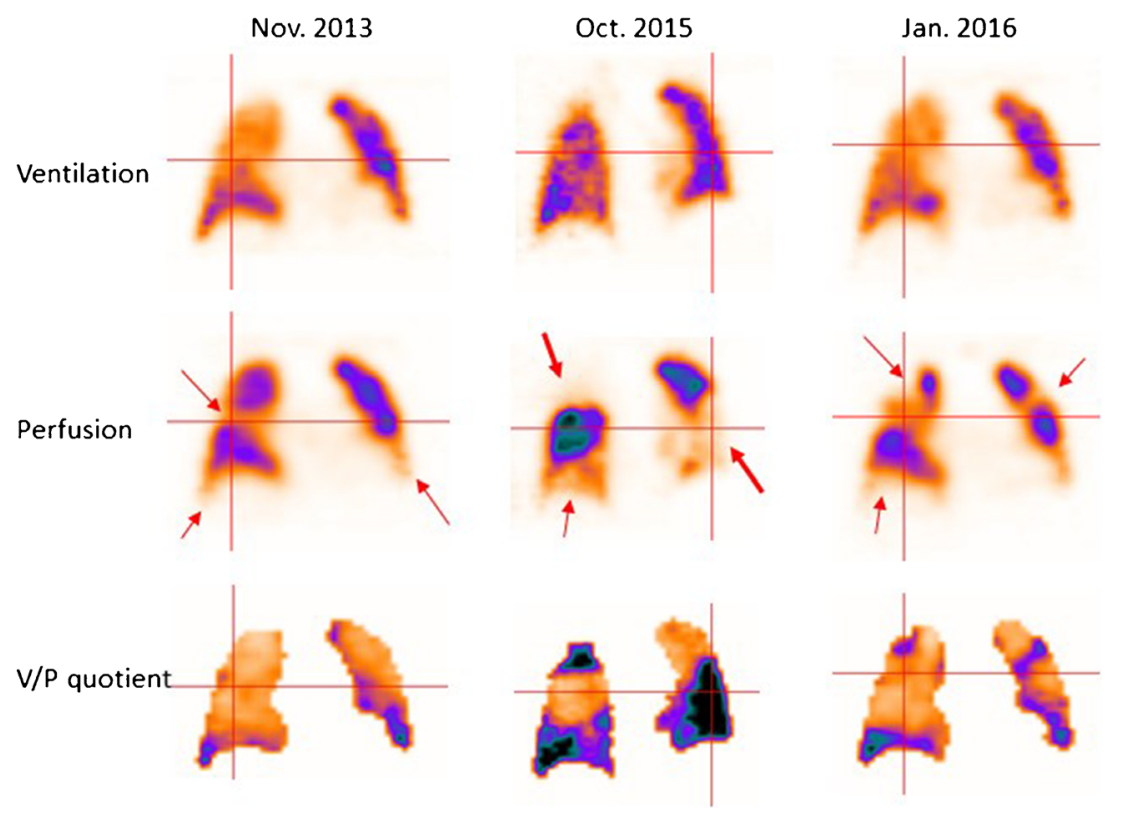




\section{Sagittal slices, left lung}

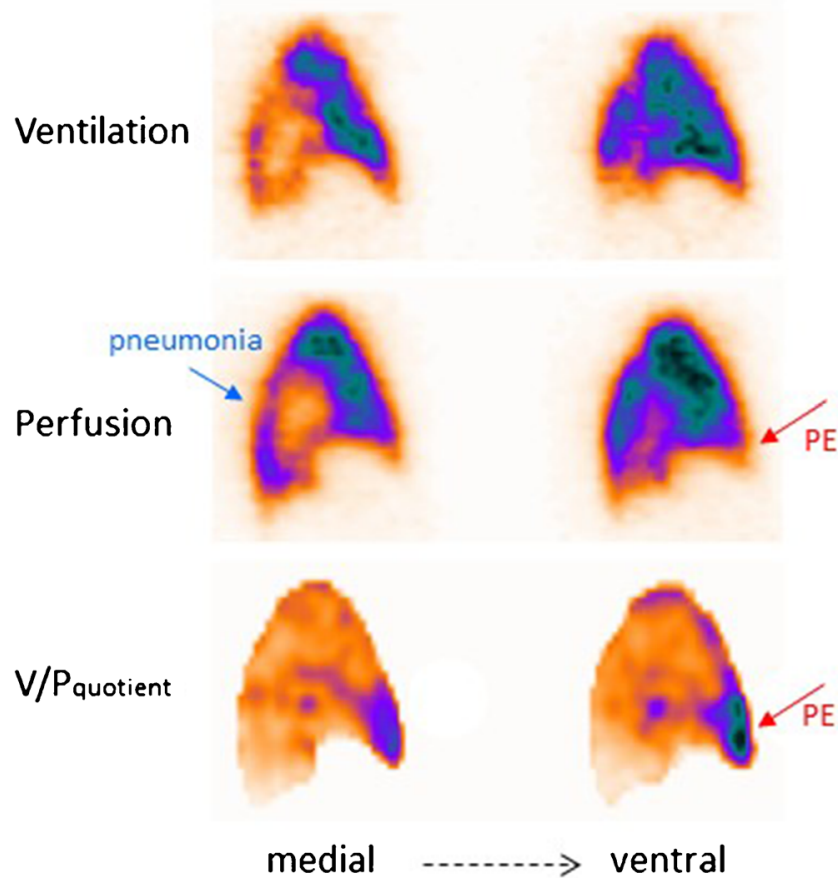

Fig. 5 Sagittal slices of the left lung in a patient with PE in the medial lobe (red arrow) and pneumonia posteriorly (blue arrow). The VP mismatch may be highlighted in $\mathrm{V} / \mathrm{P}$ quotient images

The requirements that should be met by a method used for follow-up are as follows:

- Applicability to all patients

- Low radiation dose

- High sensitivity to allow estimation of resolution of even small emboli and occurrence of new ones

$\mathrm{V} / \mathrm{P}_{\mathrm{SPECT}}$ seems ideally suited for follow-up of PE because small and large emboli are both recognised, allowing a detailed study of regression or progression of the thrombotic disease [87-89]. Furthermore, the low radiation exposure enables repeat studies. Obviously, using the same method for diagnosis and follow-up is advantageous. Research in this area is especially indicated and a predischarge $\mathrm{V} / \mathrm{P}_{\mathrm{SPECT}}$ can be recommended to help identify patients in need of life-long treatment.

\section{V/P SPECT/CT $_{\text {T }}$}

The introduction of integrated multimodality SPECT/CT cameras has enabled simultaneous acquisition of $\mathrm{V} / \mathrm{P}_{\mathrm{SPECT}}$ and $\mathrm{CT}, \mathrm{V} / \mathrm{P}_{\text {SPECT/CT }}[52-55,90]$.

The CT is usually performed as a low-dose CT scan without contrast enhancement. The additional radiation dose is approximately $1-2 \mathrm{mSv}$, so that the whole $\mathrm{V} / \mathrm{P}_{\mathrm{SPECT} / \mathrm{CT}}$ acquisition results in approximately $3-$
$4 \mathrm{mSv}$. To reduce misalignment between the SPECT and CT images, it is proposed that CT scans are acquired during continuous shallow breathing [55]. Obviously, this will affect evaluation of structures particularly in basal regions, causing artefacts.

$\mathrm{V} / \mathrm{P}_{\mathrm{SPECT} / \mathrm{CT}}$ has similar sensitivity as $\mathrm{V} / \mathrm{P}_{\text {SPECT }}$ but slightly higher specificity for $\mathrm{PE}[52,91]$. Low-dose $\mathrm{CT}$ may visualise nonthromboembolic abnormalities such as emphysema, pneumonia and other parenchymal changes or extrinsic vascular compression, which may explain perfusion defects. Figure 6 presents a case with COPD, emphysema and a mediastinal tumour. CT acquired during a full-dose breathhold scan also has disadvantages with artefacts originating from the movement of the bronchi. CT image acquisition type is dependent on the capabilities of the scanner used.

Using low-dose $\mathrm{CT}$ instead of ventilation images approximates the sensitivity for PE compared with $\mathrm{V} / \mathrm{P}_{\mathrm{SPECT} / \mathrm{CT}}$ but has a higher rate of false positives [52, 91, 92].

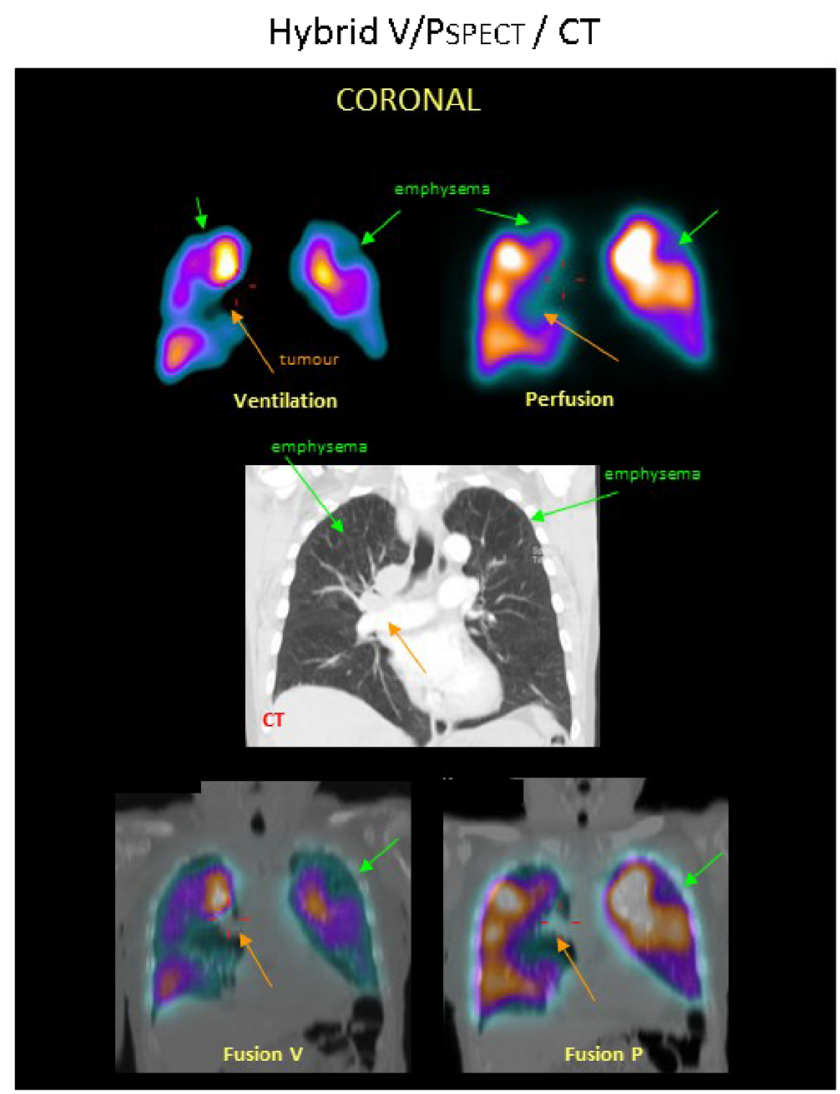

Fig. 6 A patient with COPD, emphysema and tumour. Coronal slices display uneven distribution of ventilation with a pattern of deposition of ${ }^{99}{ }^{\mathrm{m}} \mathrm{Tc}-$ Technegas ${ }^{\circledR}$ that is typical for COPD. Perfusion follows the ventilation pattern. Matched ventilation and perfusion defects are observed in both upper lobes (green arrows) and to the right of the mediastinum (orange arrows). In the medial row of the corresponding coronal CT slice, emphysema is seen in both upper lobes (green arrows), as is a tumour in the mediastinum (orange arrow). Fusion images of $\mathrm{CT}$ and ventilation SPECT and CT and perfusion SPECT are shown 
Further studies of $\mathrm{V} / \mathrm{P}_{\mathrm{SPECT} / \mathrm{CT}}$ to define its value according to good clinical practice in various categories of patients seem merited. In patients with COPD, the added value of V/P $\mathrm{P}_{\mathrm{SPECT} /}$ Ст has been validated [93].

\section{CTPA}

Computed tomography angiography of the pulmonary artery (CTPA) is imaging of the pulmonary arteries during the passage of intravenously injected iodinated contrast material. Pulmonary emboli are visualsed as so-called filling defects caused by emboli within otherwise homogenously contrastfilled pulmonary arteries. CTPA is easy to perform in a few minutes.

CTPA needs to be embedded in decision strategies that are based on the assessment of clinical PE likelihood [31]. CTPA confirms the diagnosis of PE in clinically high probability patients $(\mathrm{PPV}>95 \%)$. In the case of high pretest probability of PE and a negative CTPA, current data on diagnostic accuracy are inconsistent [94-96]; CTPA is overused in a great number of patients with low prevalence of PE [97, 98]. A PE located centrally in the pulmonary circulation can be detected by CTPA with a high PPV. The PPV decreases at segmental and subsegmental levels [96]. When clinical probability of PE is low or intermediate, CTPA may overdiagnose PE, leading to a low NPV [96].

CTPA has the potential to visualise additional pathologies other than PE such as pneumothorax, pneumonia, interstitial lung disease, pleural disease, aortic dissection and pathologies of the spine and rib cage. In the case of PE, CT is able to depict signs of right heart strain which is of prognostic importance [99-101].

\section{Risks of CTPA}

The contraindications for CTPA are linked to the use of iodinated contrast media:

- Iodine hypersensitivity. Severe pseudoallergic reactions are generally very rare (approx. $0.04 \%$, rarely fatal [102]). In an emergency scenario when CT cannot be withheld, intravenous premedication may be suitable.

- Thyroid dysfunction. Induction of hyperthyroidism and in rare cases also hypothyroidism is another complication associated with iodinated contrast media [103]. In an iodine-deficient geographical region, $2 \%$ of patients developed subclinical hyperthyroidism [104]. In unselected patients, overt hyperthyroidism occurred in $0.25 \%$ within 12 weeks [105]. Iodine-induced thyrotoxicosis is often overlooked in the elderly [106], and in the worst case, it may even cause a thyroid storm with cardiac arrest [107]. Risk factors are (potentially undiagnosed) Graves' disease and/or thyroid autonomy [108].
Patients with thyroid storm should not receive iodinated contrast media at all; in other cases, premedication with oral sodium perchlorate (and thiamazole) may be helpful. Under emergency conditions, this treatment may be initiated directly after contrast exposure. Thyroid function is routinely monitored prior to contrast application in the vast majority of radiological institutions through serum baseline TSH.

- Renal dysfunction. The most severe complication of CTPA is contrast media-induced nephropathy (CIN) or contrast-induced acute kidney injury (CI-AKI). CI-AKI is defined as an increase in serum creatinine within 48 $72 \mathrm{~h}$ after intravenous administration of low- or isoosmolarity iodinated contrast media. It carries a risk of chronic renal insufficiency, dialysis and death [100, 109]. The assumption of causality between intravenous contrast media administration and AKI has been challenged in recent publications, but data are controversial. The baseline glomerular filtration rate (eGFR) was found to be an independent predictor of AKI [110]. In two multivariate analyses, patients with an eGFR $\leq$ $43.6 \mathrm{~mL} / \mathrm{min}$ [111] or eGFR $<60 \mathrm{~mL} / \mathrm{min}$ [112], respectively, had the potential to develop CI-AKI. The odds ratios in the incidence of CI-AKI between contrastenhanced $\mathrm{CT}$ and noncontrast $\mathrm{CT}$ increased below an eGFR $<30 \mathrm{~mL} / \mathrm{min}$ [113]. In two meta-analyses, contrast-enhanced CT, compared with non-contrastenhanced CT, was not significantly associated with AKI [114, 115]. In a large single-centre retrospective cohort study, the probability of developing AKI was $10.6 \%, 10.2 \%$ and $10.9 \%$ in the contrast-enhanced, unenhanced and non-CT group [116]. However, a selection bias must be considered as only a minority of patients with a baseline serum creatinine $>1.5 \mathrm{mg} / \mathrm{dL}$ received contrast media and factors that may have influenced the clinical decision to administer contrast media could not be perceived. Randomisation of patients to receive intravenous contrast media, once not considered ethically feasible, will be necessary to fully understand the role of contrast media in precipitation of renal dysfunction [116]. Current guidelines consider intravenous contrast administration to be safe to a creatinine clearance of $30 \mathrm{~mL} / \mathrm{min} / 1.73 \mathrm{~m}^{2}$ [117]. In almost every radiological institution, a baseline serum creatinine level and/or eGFR is determined prior to intravenous contrast administration to identify patients at risk. CI-AKI was considered to be the third most common cause in hospital acquired AKI [118]; now strong evidence is provided that the incidence of CI-AKI is substantially lower [109]. AKI is a multifactorial entity, and usually more than one risk factor (contrast media, nephrotoxic drugs, hypertension, age $>70$ years, reduced cardiac output, diabetes mellitus and others) is involved [102]. 
Table 4 Summary of the pros and cons for the two principal methods to diagnose PE

\begin{tabular}{|c|c|c|c|}
\hline & $\mathrm{V} / \mathrm{P}_{\mathrm{SPECT}}$ & CTPA & Comment \\
\hline Availability & Limited & Wide & Makes CTPA indispensable \\
\hline Feasibility & Near $100 \%$ & Up to $50 \%$ & Makes $\mathrm{V} / \mathrm{P}_{\mathrm{SPECT}}$ indispensable \\
\hline Rate of nondiagnostic studies & $\begin{array}{l}1-4 \%[68,69,119, \\
120]\end{array}$ & $4-10 \%[47,96]$ & \\
\hline Sensitivity & $\geq 96 \%$ & $\geq 78 \%$ & $\begin{array}{l}\text { In high clinical probability, } 40 \% \text { needs further } \\
\text { exam }\end{array}$ \\
\hline Specificity & $\geq 97 \%$ & $\geq 98 \%$ & $\mathrm{~V} / \mathrm{P}_{\mathrm{SPECT}}$ and $\mathrm{CTPA}$ equivalent \\
\hline Effective radiation dose & $1.2-2 \mathrm{mSv}$ & $4-20 \mathrm{mSv}$ [121-127] & \\
\hline Absorbed breast radiation dose & $\approx 0.8 \mathrm{mGy}$ & $\approx 12-44$ mGy $[79,128]$ & $\mathrm{V} / \mathrm{P}_{\mathrm{SPECT}}$ crucial for young women \\
\hline Additional diagnoses & Common, important & Common, important & Highest documented rate $-\mathrm{V} / \mathrm{P}_{\text {SPECT }}$ \\
\hline $\begin{array}{l}\text { Diagnostics of chronic pulmonary } \\
\text { embolism }\end{array}$ & Reference method? & $\begin{array}{l}\text { Not useful but needed prior to } \\
\text { surgery? }\end{array}$ & $\mathrm{V} / \mathrm{P}_{\mathrm{SPECT}}$ is gold standard \\
\hline Follow-up and research & Optimal & & $\mathrm{V} / \mathrm{P}_{\mathrm{SPECT}}$ offers quantitative data \\
\hline
\end{tabular}

\section{Comparison of V/P SPECT and CTPA (see also Table 4)}

Availability CTPA is available in nearly all medical centres and community hospitals, often on a round-the-clock basis. $\mathrm{V} / \mathrm{P}_{\text {SPECT }}$ is available in fewer hospitals and seldom on a $24-$ $\mathrm{h}$ basis. CTPA has been advocated for patients with suspected $\mathrm{PE}$ and signs of shock or hypotension [31].

Feasibility and rate of nondiagnostic studies Feasibility of CTPA is restricted by the need to use intravenous iodinated contrast media. Whilst the general risk of CI-AKI seems to be overestimated [109] and iodine-induced thyrotoxicosis may be prevented by premedication, the residual risks are of a serious nature. Elevated serum creatinine and a suppressed TSH are relative contraindications to CTPA provided that $\mathrm{V} / \mathrm{P}_{\mathrm{SPECT}}$ is available $[52,96]$. High flow rates of contrast medium are a precondition for CTPA, but cannot be achieved in all patients. Motion artefacts reduce spatial resolution. In the PIOPED II trial, CTPA was inconclusive in $6.2 \%$ of patients because of poor image quality, in a subgroup this was $10.6 \%$ [96]. An increase of detector rows in CT improves resolution of CTPA, but the number of inconclusive results remained at $10 \%$ in both the 4-row and 64-row cohort, mostly due to movement artefacts and suboptimal contrast opacification [47]. In pregnant patients and those with a very low prevalence of PE (3.3\%), inconclusive results were seen in 5.9\% [129]. Nondiagnostic studies with $\mathrm{V} / \mathrm{P}_{\mathrm{SPECT}}$ may be obtained with conventional radioaerosol in patients with severe COPD, but this restriction has been mostly eliminated by the use of Technegas ${ }^{\circledR}[68,69,119,120]$. In conclusion, if contrast media-related risks are considered, feasibility of CTPA is restricted in many more patients than with $\mathrm{V} / \mathrm{P}_{\text {SPECT. }}$

In haemodynamically unstable patients, CTPA is often recommended [31, 130]. However, if a gamma camera is available, perfusion-only scintigraphy, even a single planar image, is adequate to exclude massive PE [130].

\section{Accuracy of PE diagnosis}

The lack of a satisfactory gold standard for making the diagnosis of PE poses difficulties for the assessment of sensitivity, specificity and accuracy of all diagnostic methods. Follow-up of patients for recurrence of PE as a predictor of false negative results may overcome this limitation. The comparison of $\mathrm{V} / \mathrm{P}_{\mathrm{SPECT}}$ and CTPA shows controversies. On one side, no performance difference between $\mathrm{V} / \mathrm{P}_{\text {SPECT }}$ and CTPA was seen [121]. In other studies, $\mathrm{V} / \mathrm{P}_{\mathrm{SPECT}}$ is proposed to be superior to CTPA in cases with other underlying lung diseases preventing the diagnosis of PE with CTPA. V/P $\mathrm{P}_{\text {SPECT }}$ more often provided a diagnosis of $\mathrm{PE}$ in patients with high clinical suspicion of PE and in the presence of indeterminate CTPA imaging (sensitivity 93\% vs. 83\%) [68, 94, 131, 132].

Another available benchmark is follow-up of patients for recurrence of $\mathrm{PE}$ as a predictor of false negative results. An equivalent of sensitivity was calculated on the basis of a 3month follow-up in 14,545 patients where PE was excluded by CTPA [48, 94, 95, 133-138] and in another 1865 patients where this was done by $\mathrm{V} / \mathrm{P}_{\text {SPECT }}[52,74,75,139]$ :

Sensitivity (equivalent) $[\%]=\frac{\text { PE prevalence }[\%]-\text { VTE relapse rate }[\%]}{\text { PE prevalence }[\%]} \cdot 100$

The mean sensitivity (equivalent) was $>95 \%$ for the both methods. The results do not reflect true sensitivity of the imaging test, since most PE are single events, not recorded by follow-up. On the other hand, sensitivities derived from relapse rates clearly indicate that both $\mathrm{V} / \mathrm{P}_{\text {SPECT }}$ and 16- to 64-row CTPA are able to recognise larger PE with a tendency to recurrent episodes of PE. An error rate of about $5 \%$ may be caused by false negative results of the imaging test with subsequent $\mathrm{PE}$ relapse, but may also reflect true negative results with subsequent 
primary PE events. Large multicentre management outcome studies based on $\mathrm{V} / \mathrm{P}_{\text {SPECT }}$ with a standardised diagnostic algorithm defined a priori are needed to differentiate this.

In a systematic review and meta-analysis, diagnostic performance of $\mathrm{V} / \mathrm{P}_{\mathrm{SPECT}}$ was equivalent to CTPA [121]. In head-to-head comparison studies, $\mathrm{V} / \mathrm{P}_{\mathrm{SPECT}}$ was superior to CTPA using ROC analysis [140]. This applies particularly in cases with other underlying lung diseases and when the diagnosis of PE could not be established with CTPA $[68,94,132,141]$. V/P $\mathrm{P}_{\text {SPECT }}$ more often provided a diagnosis of $\mathrm{PE}$ in patients with a high clinical suspicion of PE and in the presence of indeterminate CTPA (sensitivity $93 \%$ vs. $83 \%$ ) [131]. Superior sensitivity of $\mathrm{V} / \mathrm{P}_{\text {SPECT }}$ is best seen in patients with chronic pulmonary embolism where $\mathrm{V} / \mathrm{P}_{\text {SPECT }}$ has reference status [142], but CTPA and right heart catheterisation are also essential for patient care.

In conclusion, both techniques display specific advantages and shortcomings. $\mathrm{V} / \mathrm{P}_{\text {SPECT }}$ is superior to CTPA in cases with underlying other lung diseases and when the diagnosis of PE cannot be established with CTPA [68, 94, 131, 132].

\section{Radiation exposure}

A key objective of imaging PE is to minimise radiation exposure without sacrificing image quality and diagnostic accuracy. The amounts of radiation involved must be considered together with imaging protocols. Table 1 gives basic data on radiation exposure for $\mathrm{V} / \mathrm{P}_{\text {SPECT. }}$. With the recommended activities for ventilation and perfusion, the effective dose is $2 \mathrm{mSv}$.

In a systematic review and meta-analysis of the literature, radiation exposure was $2.12 \mathrm{mSv}$ for $\mathrm{V} / \mathrm{P}_{\text {SPECT }}$ per correct diagnosis compared with $4.96 \mathrm{mSv}$ for CTPA [121]. In clinical routine, radiation doses between 3.5 and $13.2 \mathrm{mSv}$ have been reported for CTPA [122-124]. Automated data collection as volume CT dose index and dose-length product, averaged to effective doses, varies considerably within and across facilities. Primary factors that influence dose variations are patient size (weight and chest diameter), multiphase scanning and institutional protocol choices [125]. In general, higher effective doses (> $5 \mathrm{mSv}$ ) are reported from automatically collected data [125-127].

The most critical organ in CTPA is the female breast. Absorbed radiation doses to the female breast ranging from 8.6 to $44 \mathrm{mSv}$ have been reported [79, 128, 143]. Tube current modulation is able to decrease the breast dose from 51.5 to $8.6 \mathrm{mSv}$ [143], whilst shielding is less effective [144]. Absorbed radiation dose to the female breast from $\mathrm{V} / \mathrm{P}_{\text {SPECT }}$ is $<1 \mathrm{mSv}$ [79]. Fetal-absorbed doses for
V/P $\mathrm{P}_{\text {SPECT }}$ and CTPA are similar and so small that they are unlikely to be clinically significant [79, 128, 145].

In conclusion, effective and absorbed doses are lower for $\mathrm{V} / \mathrm{P}_{\text {SPECT }}$ than for CTPA. The difference is of particular importance for the female breast, particularly in young women and critically so during pregnancy. Fetal doses are low and similar for both methods.

\section{Additional diagnostic contributions of $\mathrm{V} / \mathrm{P}_{\text {SPECT }}$}

\section{Chronic obstructive pulmonary disease}

A general unevenness of ventilation typical for COPD has been observed in $\mathrm{V} / \mathrm{P}_{\mathrm{SPECT}}$ in patients investigated for $\mathrm{PE}$ [68, 120, 146]. Perfusion is usually less affected, which leads to so-called reversed mismatch [62, 93, 119]. The degree of ventilation defects reflects varying degrees of obstruction with COPD. Figure 7 presents cases with different degrees of COPD [62, 68, 120, 147-149]:

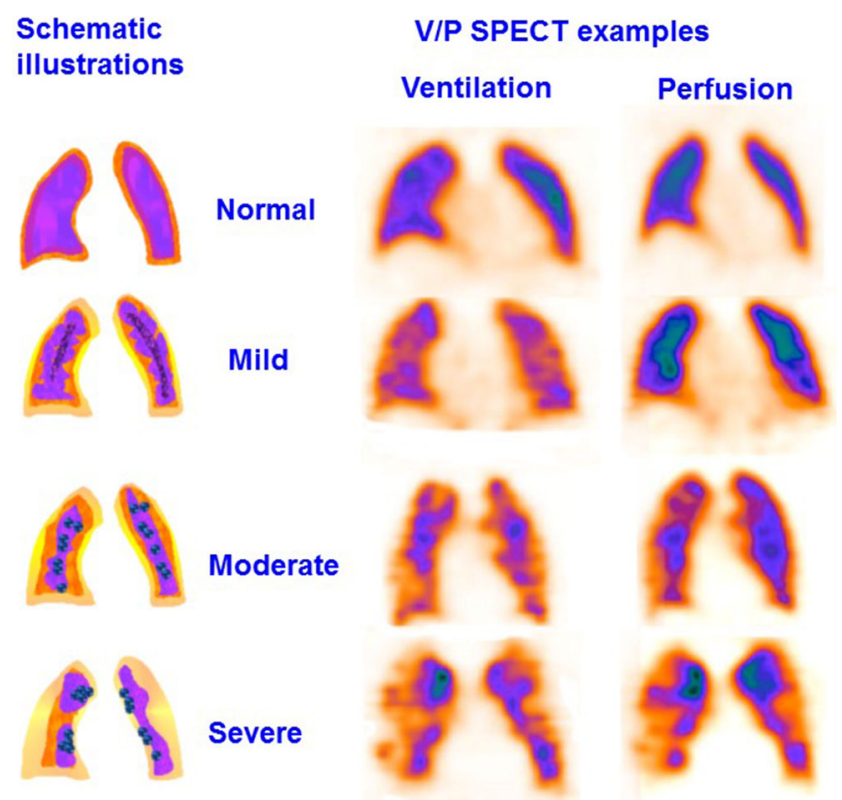

Fig. 7 Schematic presentation of the obstructive lung disease grading system and correlating representative $\mathrm{V} / \mathrm{P}_{\mathrm{SPECT}}$ images that shows different degrees of airway obstruction on coronal slices. 0: normal, even distribution of Technegas ${ }^{\circledR}$ with good peripheral penetration and without accumulation in large or small airways. 1: mild airway obstruction, slightly uneven distribution with some deposition of aerosol in small and intermediate airways. Only minor areas with reduced peripheral penetration are observed. 2: moderate airway obstruction, deposition of Technegas ${ }^{\circledR}$ in intermediate and large airways, diminished peripheral penetration with maximum accumulation in the central half of the lung. 3: severe airway obstruction, central deposition in large airways with severely impaired penetration of Technegas ${ }^{\mathbb{R}}$ and major areas with reduced or abolished function 


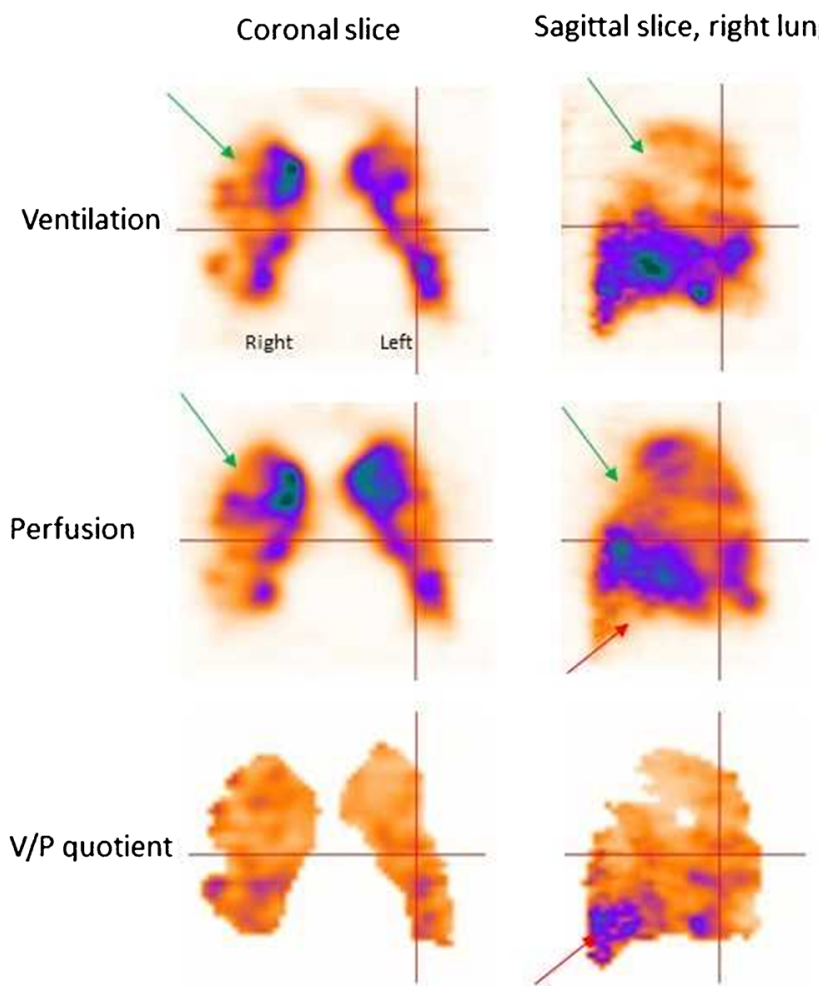

Fig. $8 \mathrm{~V} / \mathrm{P}_{\text {SPECT }}$ images showing a severe degree of airway obstruction in coronal and sagittal projections in a patient with severe COPD, emphysema (green arrow) and PE (red arrow)

- Grade 1: uneven aerosol distribution through the lung seen in mild COPD.

- Grade 2: uneven aerosol distribution and reduced Technegas ${ }^{\circledR}$ penetration to the periphery, with deposition of aerosols in small airways, seen as hotspots. This indicates moderate COPD.

- Grade 3: a severely impaired Technegas ${ }^{\circledR}$ penetration to the periphery and a central deposition of Technegas ${ }^{\circledR}$ in large airways, usually with large areas of reduced/absent ventilation. This indicates severe COPD. Figure 8 presents a case with severe COPD, emphysema and PE.

\section{Left heart failure}

Antigravitational perfusion distribution is typical for pulmonary congestion due to left heart failure. In supine patients, redistribution of perfusion towards anterior regions has been observed in $5-15 \%$ of patients with suspected PE [146, 150-152]. Based upon a measured vertical perfusion gradient, a positive predictive value of $\geq 88 \%$ to detect pulmonary congestion has been reported [151]. As ventilation is usually less affected, V/P mismatch may be observed in dorsal regions. Figure 9 presents a case with left heart failure initially and at the follow-up. This mismatch has a nonsegmental pattern (Fig. 9). It does not conform to the anatomy of pulmonary vascular architecture and should, therefore, not be misinterpreted as $\mathrm{PE}$. V/P $\mathrm{P}_{\mathrm{SPECT}}$ was recently validated against right heart catheterisation for diagnosis of pulmonary congestion in left heart failure [153].

\section{Pneumonia}

Pneumonia is a general term for conditions of lung inflammation often caused by bacterial, viral or fungal infections. It presents with nonspecific symptoms, and like other illnesses, this can lead to diagnostic problems [154]. $\mathrm{V} / \mathrm{P}_{\mathrm{SPECT}}$ shows ventilation defects, which usually exceed perfusion defects (reversed V/P mismatch) $[155,156]$. Preserved perfusion along the pleural border recognised as the 'stripe sign' is a specific sign of pneumonia [1, 157, 158]. Figure 10 presents a case with pneumonia on $\mathrm{V} / \mathrm{P}_{\mathrm{SPECT}}$ and chest X-ray. Such ventilation-perfusion patterns in pneumonia have been documented with positron emission
Fig. 9 Sagittal slices from the lung show antigravitational redistribution of perfusion in left heart failure. Ventilation is less affected causing mismatch. Mind the pattern; it is not of segmental character!
Left heart failure- initially

\section{Ventilation}
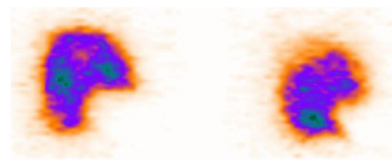

After 10 days of treatment

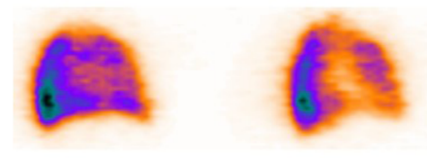

Perfusion
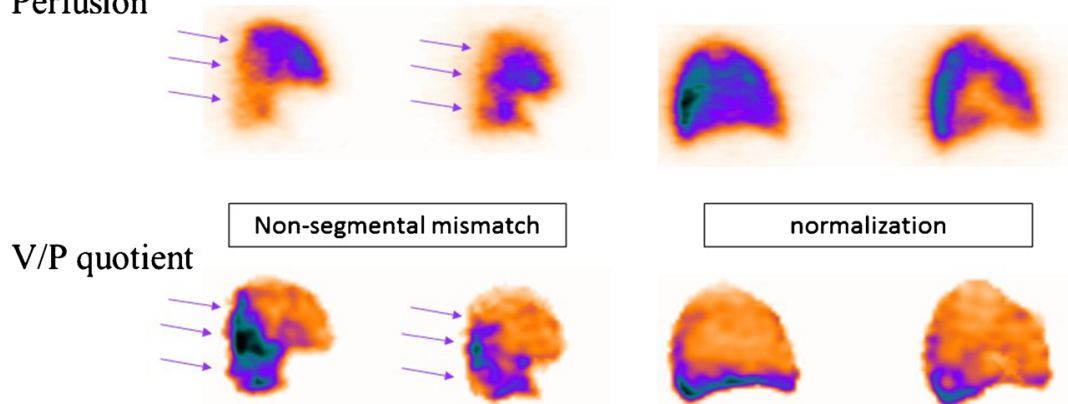

normalization
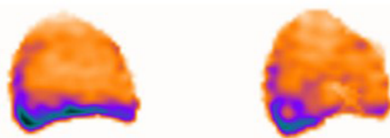


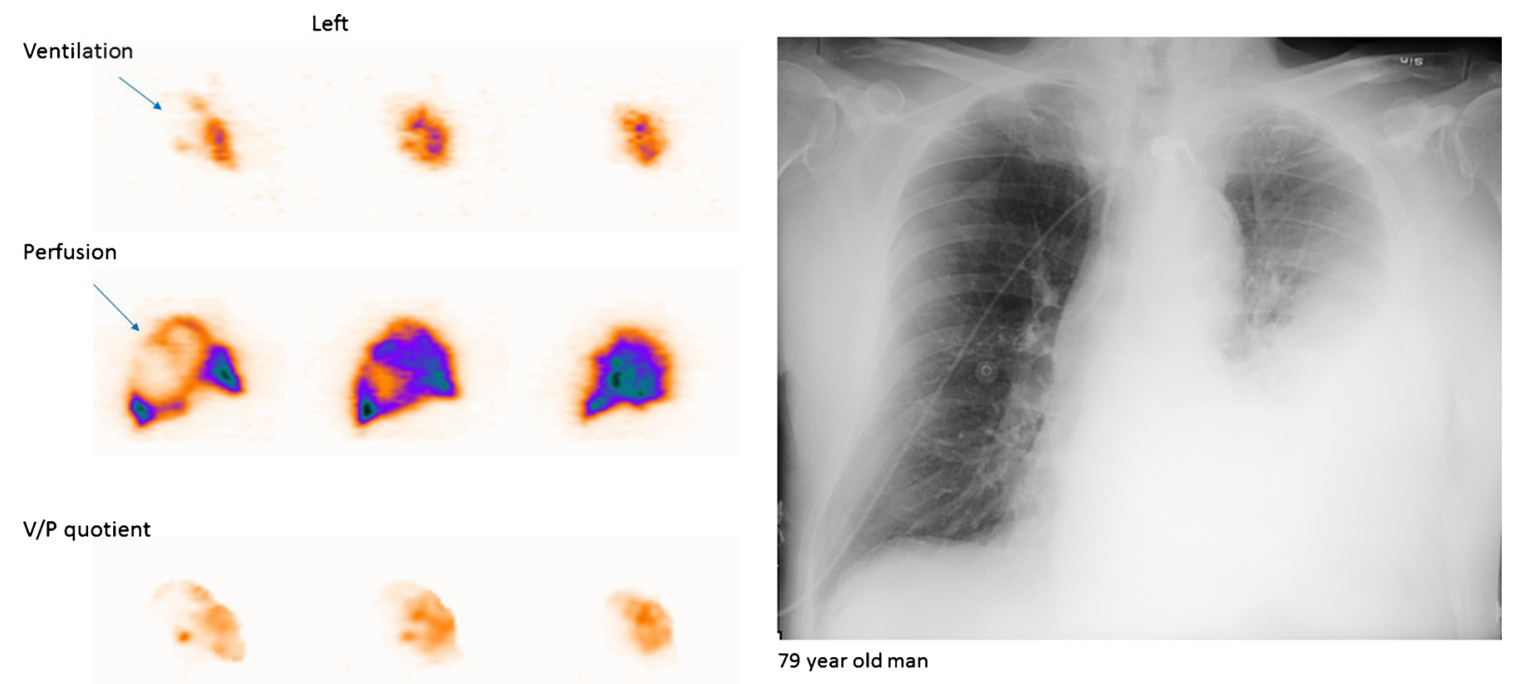

Fig. 10 Sagittal slices of the left lung in a patient with extensive pneumonia in whom the chest X-ray was interpreted as showing atelectasis (a). The left lung shows nearly absent ventilation in areas with much better perfusion. Arrow indicates stripe sign. V/P quotient highlight reverse mismatch

tomography as well [159]. Reversed-mismatched or matched V/ $\mathrm{P}$ defects typical for pneumonia can be found in $\mathrm{V} / \mathrm{P}_{\mathrm{SPECT}}$ in patients who are studied for PE. Figure 5 presents a case with $\mathrm{PE}$ and pneumonia. In some patients, $\mathrm{V} / \mathrm{P}$ defects typical for pneumonia reduce the total lung function in the absence of any structural CT defects $[146,160]$. Nevertheless, the potential of $\mathrm{V} / \mathrm{P}_{\mathrm{SPECT}}$ for diagnosis and management of pneumonia has in general not been exploited.

\section{Chronic pulmonary embolism and chronic thromboembolic pulmonary hypertension}

Chronic PE represents a condition in which perfusion defects due to pulmonary emboli have not resolved. Its clinical presentation is often insidious. It might be progressive and can lead to chronic thromboembolic pulmonary hypertension (CTEPH), right heart failure, arrhythmia and death. Figure 4 presents a case with recurrent PE and CTEPH. Figure 11 presents a case with chronic PE. CTEPH might be a consequence of repeated unrecognised small PEs. The incidence of CTEPH secondary to acute PE is around 5\% [27, 142, 161-163].

$\mathrm{V} / \mathrm{P}_{\text {scan }}$ with a sensitivity of $96 \%$ and specificity of $90 \%$ is a mainstay in the diagnosis of CTEPH, since CTPA has a sensitivity of only $\approx 50 \%$ [164]. The higher sensitivity of $\mathrm{V} / \mathrm{P}_{\text {SPECT }}$ compared with CTPA has been confirmed [165]; agreement between CTPA and scintigraphy ranged from fair $(\kappa=0.31)$ to slight $(\kappa=0.09)$ [166].

$\mathrm{V} / \mathrm{P}_{\text {scan }}$ is the imaging test of choice to exclude CTEPH [142], but is underused to diagnose CTEPH [167-169]. Pulmonary scintigraphy might differentiate among different types of CTEPH (Fig. 6).

After diagnosis of CTEPH, CTPA and right heart catheterisation are important for management decisions about therapy.

\section{Lung cancer radiotherapy planning}

Radiation therapy, alone or in combination with other treatment, plays an important role in the management of lung cancer. 'Functional image-guided lung avoidance radiotherapy' is

\section{SAGITTAL}
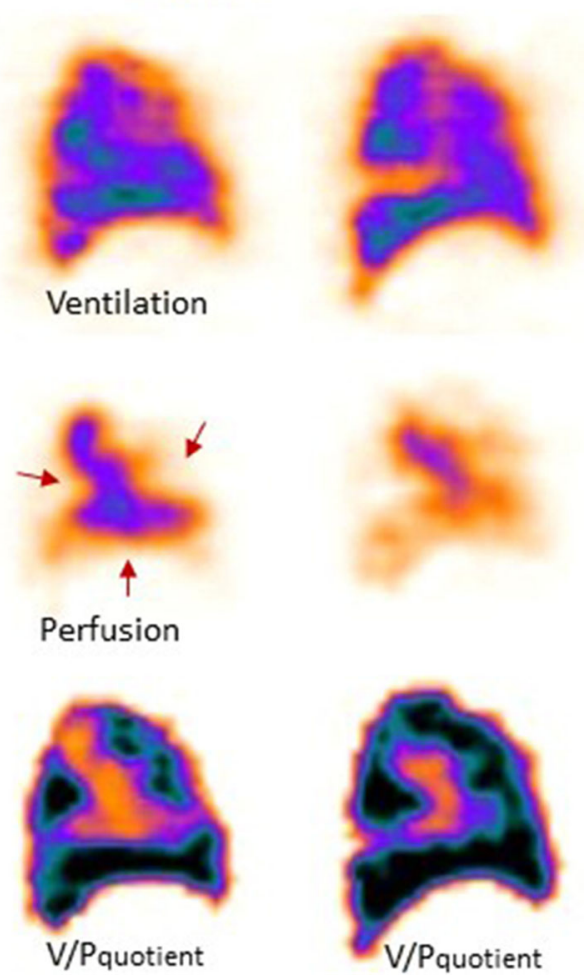

Fig. 11 Patient with chronic PE. The perfusion is only maintained in the central part of the lung, leading to large nonsegmental perfusion defects (red arrows) 
an emerging concept aimed at delivering a high radiation dose to the lung cancer tumour volume whilst minimising irradiation to the uninvolved functional lung tissue. In the future, $\mathrm{V} / \mathrm{P}_{\text {SPECT }}$ could become an interesting technique to provide the functional information needed for the planning of such treatment [170].

\section{Pregnancy}

Pregnancy poses unique circumstances in diagnosing PE:

- The incidence ofPE in pregnancy is about fivefold higher than in nonpregnant females of a similar age and is the leading nonobstetric cause of death during pregnancy in developed countries. The incidence of PE and DVT is about 1 and 3\%o, respectively [171]. The incidence is similar in all 3 trimesters [172]. The diagnostic accuracy of any test is compromised by a low prevalence of PE in this collective [147, 173].

- D-dimer is not useful because it is elevated during pregnancy [174]. CTPA has a high rate of nondiagnostic tests due to changed haemodynamics [175-179].

- CTPA leads to unique radiation hazards to the maternal breast [180].

\section{Imaging tests}

Ultrasonography To avoid unnecessary irradiation, venous compression ultrasonography can be considered. However, the diagnostic yield can be low [145].

CTPA An increased blood volume and cardiac output shortens the arrival time of intravenous contrast in the pulmonary vessels, necessitating adjustments in triggered scan delays [178, 181]. Transient influx of unopacified blood from the inferior vena cava has also been identified as a cause for poor-quality CTPA [178, 182]. Nondiagnostic CTPA scans occur in 6-36\% of patients, whilst alternative diagnoses were identified in $2-13 \%$ [145, 178, $183,184]$. Prenatal exposure to iodinated contrast media is not a risk factor for neonatal thyroid dysfunction [185].

$\mathrm{V} / \mathrm{P}_{\text {SPECT }}$ To minimise radiation, a 2-day protocol is recommended. Perfusion-only SPECT is performed on day 1, with only $50 \mathrm{MBq}{ }^{99 m}$ Tc-MAA. Because of the low incidence of pulmonary disorders in pregnant women, PE is usually excluded based on a normal perfusion pattern [186]. In the case of an abnormal perfusion pattern, anticoagulation therapy can be started until a ventilation study is performed on day 2 , using a lung-deposited activity of 20-30 MBq. This strategy leads to a high sensitivity and specificity of the examination $[145,147]$. After the first trimester, the standard 1-day $\mathrm{V} / \mathrm{P}_{\text {SPECT }}$ protocol may be considered.

\section{Dosimetry}

Fetal doses for both CTPA and perfusion SPECT are $\leq$ 0.12 mGy [145, 187-190]. The maternal absorbed dose, mainly to the breast, differs significantly and may range from 5 to $20 \mathrm{mSv}$ for CTPA $[121,125,127,145,191,192]$ and $0.5-$ $0.8 \mathrm{mSv}$ for $\mathrm{V} / \mathrm{P}_{\text {SPECT }}[145,147]$.

\section{Recommendation}

If both imaging modalities are available, $\mathrm{V} / \mathrm{P}_{\mathrm{SPECT}}$ is recommended due to the following:

- Near $100 \%$ accuracy of the diagnostic test

- The considerably lower breast radiation dose [79, 128, 147, 189, 193]

- No contraindications

\section{Diagnostic algorithm}

The likelihood of PE is assessed using a clinical prediction tool and, where indicated, the measurement of D-dimer. Where acute PTE is suspected, patients should be treated with heparin (unless contraindicated) until the test result is known. The choice of imaging test will depend on local availability but where possible $\mathrm{V} / \mathrm{P}_{\mathrm{SPECT}}$ is preferred over

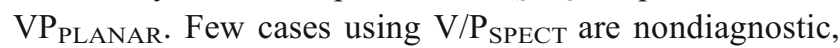
and in such instances, a further test (CTPA) is necessary to confirm or exclude PE. V/P $\mathrm{PLANAR}_{\mathrm{P}}$ has a higher indeterminate rate, in which case further investigation (usually CTPA) is necessary for diagnosis. At negative CTPA, further test should be performed in patients with remaining clinical suspicion of PE (blue arrow). With regard to the availability of V/P (planar or SPECT), it is highly variable depending on the hospital and country, but in many centres, the availability is not $24 \mathrm{~h}$ a day nor every day of the week/year.

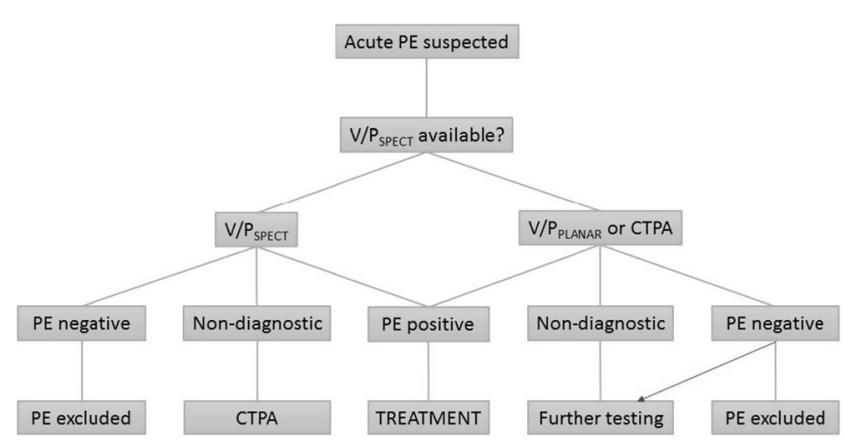


1. 'This guideline summarizes the views of the Cardiology Committee of the EANM/European Association of Vascular Medicine, experts in radiology and cardiology, and reflects recommendations for which the EANM cannot be held responsible. The recommendations should be taken into context of good practice of nuclear medicine and do not substitute for national and international legal or regulatory provisions'.

2. 'The guidelines were brought to the attention of all other EANM Committees and to the European National Societies of Nuclear Medicine. The comments and suggestions from the EANM Committees and from the European National Societies are highly appreciated and have been considered for this Guideline'.

Acknowledgments The images included in the manuscript are from Lund University Hospital.

Funding Information Open access funding provided by Lund University.

\section{Compliance with ethical standards}

The authors declare that they have no conflict of interest.

Open Access This article is distributed under the terms of the Creative Commons Attribution 4.0 International License (http:// creativecommons.org/licenses/by/4.0/), which permits unrestricted use, distribution, and reproduction in any medium, provided you give appropriate credit to the original author(s) and the source, provide a link to the Creative Commons license, and indicate if changes were made.

\section{References}

1. Bajc M, Neilly JB, Miniati M, Schuemichen C, Meignan M, Jonson B. EANM guidelines for ventilation/perfusion scintigraphy: Part 1 . Pulmonary imaging with ventilation/perfusion single photon emission tomography. Eur J Nucl Med Mol Imaging. 2009;36:1356-70. https://doi.org/10.1007/s00259-009-1170-5.

2. Bajc M, Neilly JB, Miniati M, Schuemichen C, Meignan M, Jonson B. EANM guidelines for ventilation/perfusion scintigraphy: Part 2. Algorithms and clinical considerations for diagnosis of pulmonary emboli with V/P(SPECT) and MDCT. Eur J Nucl Med Mol Imaging. 2009;36:1528-38. https://doi.org/10.1007/ s00259-009-1169-y.

3. Cohen AT, Agnelli G, Anderson FA, Arcelus JI, Bergqvist D, Brecht JG, et al. Venous thromboembolism (VTE) in Europe. The number of VTE events and associated morbidity and mortality. Thromb Haemost. 2007;98:756-64.

4. Kakkar VV, Howe CT, Flanc C, Clarke MB. Natural history of postoperative deep-vein thrombosis. Lancet (London, England). 1969;2:230-2.

5. Moser KM, Fedullo PF, LitteJohn JK, Crawford R. Frequent asymptomatic pulmonary embolism in patients with deep venous thrombosis. Jama. 1994;271:223-5.

6. White RH. The epidemiology of venous thromboembolism. Circulation. 2003;107:I4-8. https://doi.org/10.1161/01.CIR. 0000078468.11849.66.
7. Goldhaber SZ, Visani L, De Rosa M. Acute pulmonary embolism: clinical outcomes in the International Cooperative Pulmonary Embolism Registry (ICOPER). Lancet (London, England). 1999;353:1386-9.

8. Nijkeuter M, Hovens MM, Davidson BL, Huisman MV. Resolution of thromboemboli in patients with acute pulmonary embolism: a systematic review. Chest. 2006;129:192-7. https:// doi.org/10.1378/chest.129.1.192.

9. James WS 3rd, Menn SJ, Moser KM. Rapid resolution of a pulmonary embolus in man. West J Med. 1978;128:60-4.

10. Fredin H, Arborelius M Jr. Scintigraphic evaluation of pulmonary embolism after total hip replacement, using a dry $99 \mathrm{mTc}-$ microaerosol for regional ventilation. Eur J Nucl Med. 1982;7: 494-9.

11. Coakley AJ. Timing of VQ ventilation perfusion scanning. Eur $\mathbf{J}$ Nucl Med. 1995;22:1099-100.

12. Heit JA. Epidemiology of venous thromboembolism. Nat Rev Cardiol. 2015;12:464-74. https://doi.org/10.1038/nrcardio.2015. 83.

13. Borohovitz A, Weinberg MD, Weinberg I. Pulmonary embolism: care standards in 2018. Prog Cardiovasc Dis. 2018;60:613-21. https://doi.org/10.1016/j.pcad.2017.12.005.

14. Prabhu W, Soukas PA. Pulmonary embolism in 2017: increasing options for increasing incidence. R I Med J (2013). 2017;100:2732.

15. Silverstein MD, Heit JA, Mohr DN, Petterson TM, O'Fallon WM, Melton LJ 3rd. Trends in the incidence of deep vein thrombosis and pulmonary embolism: a 25-year population-based study. Arch Intern Med. 1998;158:585-93.

16. Næss IA, Christiansen SC, Romundstad P, Cannegieter SC, Rosendaal FR, Hammerstrøm J. Incidence and mortality of venous thrombosis: a population-based study. J Thromb Haemost. 2007;5:692-9. https://doi.org/10.1111/j.1538-7836.2007.02450. $\mathrm{x}$.

17. Kearon C, Ageno W, Cannegieter SC, Cosmi B, Geersing GJ, Kyrle PA. Categorization of patients as having provoked or unprovoked venous thromboembolism: guidance from the SSC of ISTH. J Thromb Haemost. 2016;14:1480-3. https://doi.org/10. 1111 /jth.13336.

18. Rosendaal FR. Venous thrombosis: a multicausal disease. Lancet (London, England). 1999;353:1167-73.

19. Giordano NJ, Jansson PS, Young MN, Hagan KA, Kabrhel C. Epidemiology, pathophysiology, stratification, and natural history of pulmonary embolism. Tech Vasc Interv Radiol. 2017;20:13540. https://doi.org/10.1053/j.tvir.2017.07.002.

20. Timp JF, Braekkan SK, Versteeg HH, Cannegieter SC. Epidemiology of cancer-associated venous thrombosis. Blood. 2013;122:1712-23. https://doi.org/10.1182/blood-2013-04460121.

21. Jensvoll H, Severinsen MT, Hammerstrøm J, Brækkan SK, Kristensen SR, Cannegieter SC, et al. Existing data sources in clinical epidemiology: the Scandinavian thrombosis and cancer cohort. Clin Epidemiol. 2015;7:401-10. https://doi.org/10.2147/ clep.s84279.

22. Stein PD, Matta F, Musani MH, Diaczok B. Silent pulmonary embolism in patients with deep venous thrombosis: a systematic review. Am J Med. 2010;123:426-31. https://doi.org/10.1016/j. amjmed.2009.09.037.

23. MacCallum P, Bowles L, Keeling D. Diagnosis and management of heritable thrombophilias. BMJ. 2014;349:g4387. https://doi. org/10.1136/bmj.g4387.

24. Miniati M, Monti S, Bottai M, Scoscia E, Bauleo C, Tonelli L, et al. Survival and restoration of pulmonary perfusion in a longterm follow-up of patients after acute pulmonary embolism. Medicine. 2006;85:253-62. https://doi.org/10.1097/01.md. 0000236952.87590.c8. 
25. Cosmi B, Nijkeuter M, Valentino M, Huisman MV, Barozzi L, Palareti G. Residual emboli on lung perfusion scan or multidetector computed tomography after a first episode of acute pulmonary embolism. Intern Emerg Med. 2011;6:521-8. https://doi.org/10. 1007/s11739-011-0577-8.

26. Sanchez O, Helley D, Couchon S, Roux A, Delaval A, Trinquart $\mathrm{L}$, et al. Perfusion defects after pulmonary embolism: risk factors and clinical significance. J Thromb Haemost. 2010;8:1248-55. https://doi.org/10.1111/j.1538-7836.2010.03844.x.

27. Hoeper MM, Madani MM, Nakanishi N, Meyer B, Cebotari S, Rubin LJ. Chronic thromboembolic pulmonary hypertension. Lancet Respir Med. 2014;2:573-82. https://doi.org/10.1016/ s2213-2600(14)70089-x.

28. Eriksson L, Wollmer P, Olsson CG, Albrechtsson U, Larusdottir $\mathrm{H}$, Nilsson R, et al. Diagnosis of pulmonary embolism based upon alveolar dead space analysis. Chest. 1989;96:357-62.

29. Meacham RR 3rd, Headley AS, Bronze MS, Lewis JB, Rester MM. Impending paradoxical embolism. Arch Intern Med. 1998;158:438-48.

30. Goldhaber SZ, Elliott CG. Acute pulmonary embolism: part I: epidemiology, pathophysiology, and diagnosis. Circulation. 2003;108:2726-9. https://doi.org/10.1161/01.cir.0000097829. $89204.0 \mathrm{c}$

31. Konstantinides SV, Torbicki A, Agnelli G, Danchin N, Fitzmaurice D, Galiè N, et al. ESC guidelines on the diagnosis and management of acute pulmonary embolism. Eur Heart J. 2014;35:3033-69, 69a-69k. https://doi.org/10.1093/eurheartj/ ehu283.

32. Miniati M, Prediletto R, Formichi B, Marini C, Di Ricco G, Tonelli L, et al. Accuracy of clinical assessment in the diagnosis of pulmonary embolism. Am J Respir Crit Care Med. 1999;159: 864-71. https://doi.org/10.1164/ajrccm.159.3.9806130.

33. Pollack CV, Schreiber D, Goldhaber SZ, Slattery D, Fanikos J, O'Neil BJ, et al. Clinical characteristics, management, and outcomes of patients diagnosed with acute pulmonary embolism in the emergency department: initial report of EMPEROR (Multicenter Emergency Medicine Pulmonary Embolism in the Real World Registry). J Am Coll Cardiol. 2011;57:700-6. https://doi.org/10.1016/j.jacc.2010.05.071.

34. Ceriani E, Combescure C, Le Gal G, Nendaz M, Perneger T, Bounameaux $\mathrm{H}$, et al. Clinical prediction rules for pulmonary embolism: a systematic review and meta-analysis. Journal of thrombosis and haemostasis : JTH. 2010;8:957-70. https://doi. org/10.1111/j.1538-7836.2010.03801.x.

35. Lucassen W, Geersing GJ, Erkens PM, Reitsma JB, Moons KG, Buller $\mathrm{H}$, et al. Clinical decision rules for excluding pulmonary embolism: a meta-analysis. Ann Intern Med. 2011;155:448-60. https://doi.org/10.7326/0003-4819-155-7-201110040-00007.

36. Di Nisio M, van Es N, Büller HR. Deep vein thrombosis and pulmonary embolism. Lancet. 2016;388:3060-73. https://doi. org/10.1016/s0140-6736(16)30514-1.

37. Wells PS, Anderson DR, Rodger M, Ginsberg JS, Kearon C, Gent $\mathrm{M}$, et al. Derivation of a simple clinical model to categorize patients probability of pulmonary embolism: increasing the models utility with the SimpliRED D-dimer. Thromb Haemost. 2000;83: 416-20.

38. Le Gal G, Righini M, Roy PM, Sanchez O, Aujesky D, Bounameaux H, et al. Prediction of pulmonary embolism in the emergency department: the revised Geneva score. Ann Intern Med. 2006;144:165-71.

39. Douma RA, Mos IC, Erkens PM, Nizet TA, Durian MF, Hovens $\mathrm{MM}$, et al. Performance of 4 clinical decision rules in the diagnostic management of acute pulmonary embolism: a prospective cohort study. Ann Intern Med. 2011;154:709-18. https://doi.org/10. 7326/0003-4819-154-11-201106070-00002.
40. Raja AS, Greenberg JO, Qaseem A, Denberg TD, Fitterman N, Schuur JD, et al. Evaluation of patients with suspected acute pulmonary embolism: best practice advice from the Clinical Guidelines Committee of the American College of Physicians. Ann Intern Med. 2015;163:701-11. https://doi.org/10.7326/ M14-1772.

41. Gibson NS, Sohne M, Kruip MJ, Tick LW, Gerdes VE, Bossuyt PM, et al. Further validation and simplification of the Wells clinical decision rule in pulmonary embolism. Thromb Haemost. 2008;99:229-34. https://doi.org/10.1160/TH07-05-0321.

42. Klok FA, Mos IC, Nijkeuter M, Righini M, Perrier A, Le Gal G, et al. Simplification of the revised Geneva score for assessing clinical probability of pulmonary embolism. Arch Intern Med. 2008;168:2131-6. https://doi.org/10.1001/archinte.168.19.2131.

43. Douma RA, Gibson NS, Gerdes VE, Büller HR, Wells PS, Perrier A, et al. Validity and clinical utility of the simplified Wells rule for assessing clinical probability for the exclusion of pulmonary embolism. Thromb Haemost. 2009;101:197-200.

44. Righini M, Van Es J, Den Exter PL, Roy PM, Verschuren F, Ghuysen A, et al. Age-adjusted D-dimer cutoff levels to rule out pulmonary embolism: the ADJUST-PE study. Jama. 2014;311: 1117-24. https://doi.org/10.1001/jama.2014.2135.

45. Le Gal G, Righini M. Controversies in the diagnosis of venous thromboembolism. J Thromb Haemost. 2015;13(Suppl 1):S259 65. https://doi.org/10.1111/jth.12937.

46. Perrier A, Roy PM, Sanchez O, Le Gal G, Meyer G, Gourdier AL, et al. Multidetector-row computed tomography in suspected pulmonary embolism. N Engl J Med. 2005;352:1760-8. https://doi. org/10.1056/NEJMoa042905.

47. Douma RA, Hofstee HM, Schaefer-Prokop C, van Waesberghe JH, Lely RJ, Kamphuisen PW, et al. Comparison of 4- and 64slice CT scanning in the diagnosis of pulmonary embolism. Thromb Haemost. 2010;103:242-6. https://doi.org/10.1160/ TH09-06-0406.

48. Freund Y, Cachanado M, Aubry A, Orsini C, Raynal PA, FéralPierssens AL, et al. Effect of the pulmonary embolism rule-out criteria on subsequent thromboembolic events among low-risk emergency department patients: the PROPER randomized clinical trial. Jama. 2018;319:559-66. https://doi.org/10.1001/jama.2017. 21904.

49. Crane S, Jaconelli T, Eragat M. Retrospective validation of the pulmonary embolism rule-out criteria rule in 'PE unlikely' patients with suspected pulmonary embolism. Eur J Emerg Med. 2018;25:185-90. https://doi.org/10.1097/mej. 0000000000000442 .

50. Baile EM, King GG, Müller NL, D'Yachkova Y, Coche EE, Paré $\mathrm{PD}$, et al. Spiral computed tomography is comparable to angiography for the diagnosis of pulmonary embolism. Am J Respir Crit Care Med. 2000;161:1010-5. https://doi.org/10.1164/ajrccm.161. 3.9904067 .

51. Fields JM, Davis J, Girson L, Au A, Potts J, Morgan CJ, et al. Transthoracic echocardiography for diagnosing pulmonary embolism: a systematic review and meta-analysis. J Am Soc Echocardiogr. 2017;30:714-23 e4. https://doi.org/10.1016/j. echo.2017.03.004.

52. Gutte H, Mortensen J, Jensen CV, Johnbeck CB, von der Recke P, Petersen CL, et al. Detection of pulmonary embolism with combined ventilation-perfusion SPECT and low-dose CT: head-tohead comparison with multidetector CT angiography. J Nucl Med. 2009;50:1987-92. https://doi.org/10.2967/jnumed.108. 061606.

53. Le Roux PY, Pelletier-Galarneau M, De Laroche R, Hofman MS, Zuckier LS, Roach P, et al. Pulmonary scintigraphy for the diagnosis of acute pulmonary embolism: a survey of current practices in Australia, Canada, and France. J Nucl Med. 2015;56:1212-7. https://doi.org/10.2967/jnumed.115.157743. 
54. Le Roux PY, Robin P, Salaun PY. New developments and future challenges of nuclear medicine and molecular imaging for pulmonary embolism. Thromb Res. 2018;163:236-41. https://doi.org/ 10.1016/j.thromres.2017.06.031.

55. Roach PJ, Schembri GP, Bailey DL. V/Q scanning using SPECT and SPECT/CT. J Nucl Med. 2013;54:1588-96. https://doi.org/ 10.2967/jnumed.113.124602.

56. Ikesaka R, Carrier M. Clinical significance and management of subsegmental pulmonary embolism. J Thromb Thrombolysis. 2015;39:311-4. https://doi.org/10.1007/s11239-015-1169-7.

57. Schembri GP, Roach PJ, Bailey DL, Freeman L. Artifacts and anatomical variants affecting ventilation and perfusion lung imaging. Semin Nucl Med. 2015;45:373-91. https://doi.org/10.1053/j. semnuclmed.2015.02.009.

58. Jögi J, Jonson B, Ekberg M, Bajc M. Ventilation-perfusion SPECT with 99mTc-DTPA versus Technegas: a head-to-head study in obstructive and nonobstructive disease. J Nucl Med. 2010;51:735-41. https://doi.org/10.2967/jnumed.109.073957.

59. Burch WM, Tetley IJ, Gras JL. Technetium-99m 'pseudogas' for diagnostic studies in the lung. Clin Phys Physiol Meas. 1984;5: $79-85$.

60. Lemb M, Oei TH, Eifert H, Günther B. Technegas: a study of particle structure, size and distribution. Eur J Nucl Med. 1993;20:576-9.

61. Bajc M, Markstad H, Jarenbäck L, Tufvesson E, Bjermer L, Jögi J. Grading obstructive lung disease using tomographic pulmonary scintigraphy in patients with chronic obstructive pulmonary disease (COPD) and long-term smokers. Ann Nucl Med. 2015;29: 91-9. https://doi.org/10.1007/s12149-014-0913-y.

62. Jögi J, Ekberg M, Jonson B, Bozovic G, Bajc M. Ventilation/ perfusion SPECT in chronic obstructive pulmonary disease: an evaluation by reference to symptoms, spirometric lung function and emphysema, as assessed with HRCT. Eur J Nucl Med Mol Imaging. 2011;38:1344-52. https://doi.org/10.1007/s00259-0111757-5.

63. Heck LL, Duley JW Jr. Statistical considerations in lung imaging with $99 \mathrm{mTc}$ albumin particles. Radiology. 1974;113:675-9. https://doi.org/10.1148/113.3.675.

64. Ciofetta G, Piepsz A, Roca I, Fisher S, Hahn K, Sixt R, et al. Guidelines for lung scintigraphy in children. Eur J Nucl Med Mol Imaging. 2007;34:1518-26. https://doi.org/10.1007/s00259007-0485-3.

65. Palmer J, Bitzén U, Jonson B, Bajc M. Comprehensive ventilation/perfusion SPECT. J Nucl Med. 2001;42:1288-94.

66. Bajc M, Olsson CG, Palmer J, Jonson B. Quantitative ventilation/ perfusion SPECT (QV/PSPECT): a primary method for diagnosis of pulmonary embolism. In: Freeman LM, editor. Nuclear Medicine Annual. Philadelphia: Lippincott Williams \& Wilkins; 2004. p. 173-86.

67. Le Roux PY, Robin P, Delluc A, Abgral R, Le Duc-Pennec A, Nowak E, et al. V/Q SPECT interpretation for pulmonary embolism diagnosis: which criteria to use? J Nucl Med. 2013;54:107781. https://doi.org/10.2967/jnumed.112.113639.

68. Bajc M, Olsson B, Palmer J, Jonson B. Ventilation/perfusion SPECT for diagnostics of pulmonary embolism in clinical practice. J Intern Med. 2008;264:379-87. https://doi.org/10.1111/j. 1365-2796.2008.01980.x.

69. Grüning T, Drake BE, Farrell SL, Nokes T. Three-year clinical experience with VQ SPECT for diagnosing pulmonary embolism: diagnostic performance. Clin Imaging. 2014;38:831-5. https:// doi.org/10.1016/j.clinimag.2014.04.003.

70. Angriman F, Ferreyro BL, Posadas-Martinez ML, Giunta D, Vazquez FJ, Vollmer WM. Wells score and poor outcomes among adult patients with subsegmental pulmonary embolism: a cohort study. Clin Appl Thromb Hemost. 2015;21:539-45. https://doi. org/10.1177/1076029614559772.
71. Begic A, Opanković O, Begović-Hadžimuratović S, Konjić M, Krekić S. Ventilation/perfusion tomography - V/P-SPECT vs planar technique. CRIM. 2014;1:205-9.

72. Corbus HF, Seitz JP, Larson RK, Stobbe DE, Wooten W, Sayre JW, et al. Diagnostic usefulness of lung SPET in pulmonary thromboembolism: an outcome study. Nucl Med Commun. 1997;18:897-906.

73. Le Duc-Pennec A, Le Roux PY, Cornily JC, Jaffrelot M, Delluc A, de Saint-Martin L, et al. Diagnostic accuracy of single-photon emission tomography ventilation/perfusion lung scan in the diagnosis of pulmonary embolism. Chest. 2012;141:381-7. https://doi. org/10.1378/chest.11-0090.

74. Le Roux PY, Palard X, Robin P, Delluc A, Abgral R, Querellou S, et al. Safety of ventilation/perfusion single photon emission computed tomography for pulmonary embolism diagnosis. Eur J Nucl Med Mol Imaging. 2014;41:1957-64. https://doi.org/10.1007/ s00259-014-2763-1.

75. Leblanc M, Leveillée F, Turcotte E. Prospective evaluation of the negative predictive value of V/Q SPECT using 99mTc-Technegas. Nucl Med Commun. 2007;28:667-72. https://doi.org/10.1097/ MNM.0b013e32827a8e99.

76. Reinartz P, Wildberger JE, Schaefer W, Nowak B, Mahnken AH, Buell U. Tomographic imaging in the diagnosis of pulmonary embolism: a comparison between V/Q lung scintigraphy in SPECT technique and multislice spiral CT. J Nucl Med. 2004;45:1501-8.

77. Quirce R, Ibáñez-Bravo S, Jiménez-Bonilla J, MartínezRodríguez I, Martínez-Amador N, Ortega-Nava F, et al. Contribution of V/Q SPECT to planar scintigraphy in the diagnosis of pulmonary embolism. Rev Esp Med Nucl Imagen Mol. 2014;33:153-8. https://doi.org/10.1016/j.remn.2013.12.001.

78. Kan Y, Yuan L, Meeks JK, Li C, Liu W, Yang J. The accuracy of V/Q SPECT in the diagnosis of pulmonary embolism: a metaanalysis. Acta Radiol. 2015;56:565-72. https://doi.org/10.1177/ 0284185114533682.

79. Astani SA, Davis LC, Harkness BA, Supanich MP, Dalal I Detection of pulmonary embolism during pregnancy: comparing radiation doses of CTPA and pulmonary scintigraphy. Nucl Med Commun. 2014;35:704-11. https://doi.org/10.1097/MNM. 0000000000000114 .

80. Cei M, Mumoli N, Mariotti F, Pardelli R. The importance of clinical suspicion in diagnosing pulmonary embolism: a case of falsepositive high probability radionuclide perfusion lung scan. Eur $\mathrm{J}$ Emerg Med. 2004;11:234-6.

81. Freeman LM, Krynyckyi B, Zuckier LS. Enhanced lung scan diagnosis of pulmonary embolism with the use of ancillary scintigraphic findings and clinical correlation. Semin Nucl Med. 2001;31:143-57.

82. Petersson J, Rohdin M, Sánchez-Crespo A, Nyrén S, Jacobsson H, Larsson SA, et al. Posture primarily affects lung tissue distribution with minor effect on blood flow and ventilation. Respir Physiol Neurobiol. 2007;156:293-303. https://doi.org/10.1016/j.resp. 2006.11.001.

83. Couturaud F. Guided duration of anticoagulation after unprovoked venous thromboembolism using D-dimer testing. Eur Respir J. 2016;47:1313-4. https://doi.org/10.1183/13993003.00212-2016.

84. Couturaud F, Sanchez O, Pernod G, Mismetti P, Jego P, Duhamel E, et al. Six months vs extended oral anticoagulation after a first episode of pulmonary embolism: the PADIS-PE randomized clinical trial. Jama. 2015;314:31-40. https://doi.org/10.1001/jama. 2015.7046.

85. Alhadad A, Miniati M, Alhadad H, Gottsater A, Bajc M. The value of tomographic ventilation/perfusion scintigraphy (V/PSPECT) for follow-up and prediction of recurrence in pulmonary embolism. Thromb Res. 2012;130:877-81. https://doi.org/ 10.1016/j.thromres.2012.09.002. 
86. Elf JE, Jögi J, Bajc M. Home treatment of patients with small to medium sized acute pulmonary embolism. J Thromb Thrombolysis. 2015;39:166-72. https://doi.org/10.1007/s11239014-1097-y.

87. Begic A, Jögi J, Hadziredzepovic A, Kucukalic-Selimovic E, Begovic-Hadzimuratovic S, Bajc M. Tomographic ventilation/ perfusion lung scintigraphy in the monitoring of the effect of treatment in pulmonary embolism: serial follow-up over a 6-month period. Nucl Med Commun. 2011;32:508-14. https://doi.org/10. 1097/MNM.0b013e328344dfd5.

88. Begic A, Opanković E, Čukić V, Rustempašić M, Bašić A, Miniati $\mathrm{M}$, et al. Impact of ventilation/perfusion single-photon emission computed tomography on treatment duration of pulmonary embolism. Nucl Med Commun. 2015;36:162-7. https://doi.org/10. 1097/MNM.0000000000000224.

89. Olsson CG, Bitzén U, Olsson B, Magnusson P, Carlsson MS, Jonson B, et al. Outpatient tinzaparin therapy in pulmonary embolism quantified with ventilation/perfusion scintigraphy. Med Sci Monit. 2006;12:PI9-13.

90. Bajc M. Potential of hybrid V/P SPECT-low-dose CT in lung diagnostics. Breathe. 2012;9:49-60. https://doi.org/10.1183/ 20734735.018412.

91. Le Roux PY, Robin P, Delluc A, Abgral R, Palard X, Tissot V, et al. Additional value of combining low-dose computed tomography to V/Q SPECT on a hybrid SPECT-CT camera for pulmonary embolism diagnosis. Nucl Med Commun. 2015;36:922-30. https://doi.org/10.1097/mnm.0000000000000351.

92. Palmowski K, Oltmanns U, Kreuter M, Mottaghy FM, Palmowski $\mathrm{M}$, Behrendt FF. Diagnosis of pulmonary embolism: conventional ventilation/perfusion SPECT is superior to the combination of perfusion SPECT and nonenhanced CT. Respiration. 2014;88: 291-7. https://doi.org/10.1159/000365817.

93. Jögi J, Markstad H, Tufvesson E, Bjermer L, Bajc M. The added value of hybrid ventilation/perfusion SPECT/CT in patients with stable COPD or apparently healthy smokers. Cancer-suspected $\mathrm{CT}$ findings in the lungs are common when hybrid imaging is used. Int J Chron Obstruct Pulmon Dis. 2015;10:25-30. https:// doi.org/10.2147/copd.S73423.

94. Moores L, Kline J, Portillo AK, Resano S, Vicente A, Arrieta P, et al. Multidetector computed tomographic pulmonary angiography in patients with a high clinical probability of pulmonary embolism. J Thromb Haemost. 2016;14:114-20. https://doi.org/10. 1111/jth. 13188

95. Robert-Ebadi H, Glauser F, Planquette B, Moumneh T, Le Gal G, Righini M. Safety of multidetector computed tomography pulmonary angiography to exclude pulmonary embolism in patients with a likely pretest clinical probability. J Thromb Haemost. 2017;15: 1584-90. https://doi.org/10.1111/jth.13746.

96. Stein PD, Fowler SE, Goodman LR, Gottschalk A, Hales CA, Hull RD, et al. Multidetector computed tomography for acute pulmonary embolism. N Engl J Med. 2006;354:2317-27. https:// doi.org/10.1056/NEJMoa052367.

97. Feng LB, Pines JM, Yusuf HR, Grosse SD. U.S. trends in computed tomography use and diagnoses in emergency department visits by patients with symptoms suggestive of pulmonary embolism, 2001-2009. Acad Emerg Med. 2013;20:1033-40. https:// doi.org/10.1111/acem.12221.

98. Hutchinson BD, Navin P, Marom EM, Truong MT, Bruzzi JF. Overdiagnosis of pulmonary embolism by pulmonary CT angiography. AJR Am J Roentgenol. 2015;205:271-7. https://doi.org/10. 2214/ajr.14.13938.

99. Becattini C, Agnelli G, Germini F, Vedovati MC. Computed tomography to assess risk of death in acute pulmonary embolism: a meta-analysis. Eur Respir J. 2014;43:1678-90. https://doi.org/10. 1183/09031936.00147813.
100. Meinel FG, Nance JW Jr, Schoepf UJ, Hoffmann VS, Thierfelder $\mathrm{KM}$, Costello P, et al. Predictive value of computed tomography in acute pulmonary embolism: systematic review and meta-analysis. Am J Med. 2015;128:747-59.e2. https://doi.org/10.1016/j. amjmed.2015.01.023.

101. Stein PD, Matta F, Sedrick JA, Saleh T, Badshah A, Denier JE. Ancillary findings on CT pulmonary angiograms and abnormalities on chest radiographs in patients in whom pulmonary embolism was excluded. Clin Appl Thromb Hemost. 2012;18:201-5. https://doi.org/10.1177/1076029611416640.

102. ACR manual on contrast media. Version 10.3. 2017.

103. Rhee CM, Bhan I, Alexander EK, Brunelli SM. Association between iodinated contrast media exposure and incident hyperthyroidism and hypothyroidism. Arch Intern Med. 2012;172:153-9. https://doi.org/10.1001/archinternmed.2011.677.

104. Jarvis C, Simcox K, Tamatea JA, McAnulty K, Meyer-Rochow GY, Conaglen JV, et al. A low incidence of iodine-induced hyperthyroidism following administration of iodinated contrast in an iodine-deficient region. Clin Endocrinol (Oxf). 2016;84:558-63. https://doi.org/10.1111/cen.12818.

105. Hintze G, Blombach O, Fink H, Burkhardt U, Köbberling J. Risk of iodine-induced thyrotoxicosis after coronary angiography: an investigation in 788 unselected subjects. Eur J Endocrinol. 1999;140:264-7.

106. Foppiani L, Cascio C, Lo PG. Iodine-induced hyperthyroidism as combination of different etiologies: an overlooked entity in the elderly. Aging Clin Exp Res. 2016;28:1023-7. https://doi.org/10. 1007/s40520-015-0483-4.

107. Alkhuja S, Pyram R, Odeyemi O. In the eye of the storm: iodinated contrast medium induced thyroid storm presenting as cardiopulmonary arrest. Heart Lung. 2013;42:267-9. https://doi.org/10. 1016/j.hrtlng.2013.04.002.

108. Dave A, Ludlow J, Malaty J. Thyrotoxicosis: an under-recognised aetiology. BMJ Case Rep. 2015;2015. https://doi.org/10.1136/bcr2014-208119.

109. McDonald RJ, McDonald JS, Newhouse JH, Davenport MS. Controversies in contrast material-induced acute kidney injury: closing in on the truth? Radiology. 2015;277:627-32. https://doi. org/10.1148/radiol.2015151486.

110. Caspi O, Habib M, Cohen Y, Kerner A, Roguin A, Abergel E, et al. Acute kidney injury after primary angioplasty: is contrastinduced nephropathy the culprit? J Am Heart Assoc. 2017;6. https://doi.org/10.1161/JAHA.117.005715.

111. Kume K, Yasuoka Y, Adachi H, Noda Y, Hattori S, Araki R, et al. Impact of contrast-induced acute kidney injury on outcomes in patients with ST-segment elevation myocardial infarction undergoing primary percutaneous coronary intervention. Cardiovasc Revasc Med. 2013;14:253-7. https://doi.org/10.1016/j.carrev. 2013.07.009.

112. Celik O, Ozturk D, Akin F, Ayca B, Yalcin AA, Erturk M, et al. Association between contrast media volume-glomerular filtration rate ratio and contrast-induced acute kidney injury after primary percutaneous coronary intervention. Angiology. 2015;66:519-24. https://doi.org/10.1177/0003319714542277.

113. Davenport MS, Khalatbari S, Cohan RH, Dillman JR, Myles JD, Ellis JH. Contrast material-induced nephrotoxicity and intravenous low-osmolality iodinated contrast material: risk stratification by using estimated glomerular filtration rate. Radiology. 2013;268:719-28. https://doi.org/10.1148/radiol.13122276.

114. Aycock RD, Westafer LM, Boxen JL, Majlesi N, Schoenfeld EM, Bannuru RR. Acute kidney injury after computed tomography: a meta-analysis. Ann Emerg Med. 2018;71:44-53.e4. https://doi. org/10.1016/j.annemergmed.2017.06.041.

115. McDonald JS, McDonald RJ, Carter RE, Katzberg RW, Kallmes DF, Williamson EE. Risk of intravenous contrast materialmediated acute kidney injury: a propensity score-matched study 
stratified by baseline-estimated glomerular filtration rate. Radiology. 2014;271:65-73. https://doi.org/10.1148/radiol. 13130775.

116. Hinson JS, Mistry B, Hsieh YH, Risko N, Scordino D, Paziana K, et al. Using the electronic medical record to reduce unnecessary ordering of coagulation studies for patients with chest pain. West $\mathbf{J}$ Emerg Med. 2017;18:267-9. https://doi.org/10.5811/westjem. 2016.12.31927.

117. ESUR guidelines on contrast media. Version 10.0. 2018.

118. Deek H, Newton P, Sheerin N, Noureddine S, Davidson PM. Contrast media induced nephropathy: a literature review of the available evidence and recommendations for practice. Aust Crit Care. 2014;27:166-71. https://doi.org/10.1016/j.aucc.2013.12. 002

119. Bajc M, Chen Y, Wang J, Li XY, Shen WM, Wang CZ, et al. Identifying the heterogeneity of COPD by V/P SPECT: a new tool for improving the diagnosis of parenchymal defects and grading the severity of small airways disease. Int J Chron Obstruct Pulmon Dis. 2017;12:1579-87. https://doi.org/10.2147/copd.S131847.

120. Nasr A, Lindqvist A, Bajc M. Ventilation defect typical for COPD is frequent among patients suspected for pulmonary embolism but does not prevent the diagnosis of PE by VP SPECT. EC Pulmonol Respir Med. 2017;4:85-91.

121. Phillips JJ, Straiton J, Staff RT. Planar and SPECT ventilation/ perfusion imaging and computed tomography for the diagnosis of pulmonary embolism: a systematic review and meta-analysis of the literature, and cost and dose comparison. Eur J Radiol. 2015;84:1392-400. https://doi.org/10.1016/j.ejrad.2015.03.013.

122. Bucher AM, Kerl MJ, Albrecht MH, Beeres M, Ackermann H, Wichmann JL, et al. Systematic comparison of reduced tube current protocols for high-pitch and standard-pitch pulmonary CT angiography in a large single-center population. Acad Radiol. 2016;23:619-27. https://doi.org/10.1016/j.acra.2016.01.003.

123. De Zordo T, von Lutterotti K, Dejaco C, Soegner PF, Frank R, Aigner $\mathrm{F}$, et al. Comparison of image quality and radiation dose of different pulmonary CTA protocols on a 128-slice CT: high-pitch dual source CT, dual energy CT and conventional spiral CT. Eur Radiol. 2012;22:279-86. https://doi.org/10.1007/s00330-0112251-y.

124. Elbakri IA, Kirkpatrick IDC. Survey of clinical doses from computed tomography examinations in the Canadian province of Manitoba. Radiat Prot Dosim. 2013;157:525-35. https://doi.org/ 10.1093/rpd/nct168.

125. Smith-Bindman R, Wang Y, Yellen-Nelson TR, Moghadassi M, Wilson N, Gould R, et al. Predictors of CT radiation dose and their effect on patient care: a comprehensive analysis using automated data. Radiology. 2017;282:182-93. https://doi.org/10.1148/radiol. 2016151391

126. Liang CR, Chen PXH, Kapur J, Ong MKL, Quek ST, Kapur SC. Establishment of institutional diagnostic reference level for computed tomography with automated dose-tracking software. J Med Radiat Sci. 2017;64:82-9. https://doi.org/10.1002/jmrs.210.

127. MacGregor K, Li I, Dowdell T, Gray BG. Identifying institutional diagnostic reference levels for $\mathrm{CT}$ with radiation dose index monitoring software. Radiology. 2015;276:507-17. https://doi.org/10. 1148/radiol.2015141520.

128. Isidoro J, Gil P, Costa G, Pedroso de Lima J, Alves C, Ferreira NC. Radiation dose comparison between V/P-SPECT and CTangiography in the diagnosis of pulmonary embolism. Phys Med. 2017;41:93-6. https://doi.org/10.1016/j.ejmp.2017.04.026.

129. van Mens TE, Scheres LJ, de Jong PG, Leeflang MM, Nijkeuter M, Middeldorp S. Imaging for the exclusion of pulmonary embolism in pregnancy. Cochrane Database Syst Rev. 2017;1: CD011053. https://doi.org/10.1002/14651858.CD011053.pub2.

130. Waxman AD, Bajc M, Brown M, Fahey FH, Freeman LM, Haramati LB, et al. Appropriate use criteria for ventilation- perfusion imaging in pulmonary embolism: summary and excerpts. J Nucl Med. 2017;58:13N-5N.

131. Ibáñez-Bravo S, Banzo I, Quirce R, Martínez-Rodríguez I, Jímenez-Bonilla J, Martínez-Amador N, et al. Ventilation/ perfusion SPECT lung scintigraphy and computed tomography pulmonary angiography in patients with clinical suspicion of pulmonary embolism. Rev Esp Med Nucl Imagen Mol. 2016;35: 215-20. https://doi.org/10.1016/j.remn.2015.12.008.

132. Mahdavi R, Caronia J, Fayyaz J, Panagopoulos G, Lessnau KD, Scharf SC, et al. Agreement between SPECT V/Q scan and CT angiography in patients with high clinical suspicion of PE. Ann Nucl Med. 2013;27:834-8. https://doi.org/10.1007/s12149-0130753-1.

133. Hammer MM, Litt HI. Risk of pulmonary embolism after a prior negative CT pulmonary angiogram. Am J Emerg Med. 2016;34: 1968-72. https://doi.org/10.1016/j.ajem.2016.07.002.

134. Mos IC, Douma RA, Erkens PM, Kruip MJ, Hovens MM, van Houten AA, et al. Diagnostic outcome management study in patients with clinically suspected recurrent acute pulmonary embolism with a structured algorithm. Thromb Res. 2014;133:1039-44. https://doi.org/10.1016/j.thromres.2014.03.050.

135. Pesavento R, de Conti G, Minotto I, Filippi L, Mongiat M, de Faveri $\mathrm{D}$, et al. The value of 64-detector row computed tomography for the exclusion of pulmonary embolism. Thromb Haemost. 2011;105:901-7. https://doi.org/10.1160/TH10-10-0638.

136. van der Hulle T, Cheung WY, Kooij S, Beenen LFM, van Bemmel T, van Es J, et al. Simplified diagnostic management of suspected pulmonary embolism (the YEARS study): a prospective, multicentre, cohort study. Lancet. 2017;390:289-97. https://doi. org/10.1016/S0140-6736(17)30885-1.

137. van der Hulle T, van Es N, den Exter PL, van Es J, Mos ICM, Douma RA, et al. Is a normal computed tomography pulmonary angiography safe to rule out acute pulmonary embolism in patients with a likely clinical probability? A patient-level meta-analysis. Thromb Haemost. 2017;117:1622-9. https://doi.org/10.1160/ TH17-02-0076.

138. van der Pol LM, van der Hulle T, Mairuhu ATA, Huisman MV, Klok FA. Combination of pulmonary embolism rule-out criteria and YEARS algorithm in a European cohort of patients with suspected pulmonary embolism. Thromb Haemost. 2018;118: 547-52. https://doi.org/10.1055/s-0038-1623535.

139. Parekh A, Graham R, Redman S. Ventilation/perfusion singlephoton emission computed tomography: a service evaluation. Nucl Med Commun. 2017;38:672-5. https://doi.org/10.1097/ MNM.0000000000000693.

140. Meng JJ, Zhang LJ, Wang Q, Fang W, Dai HJ, Yan J, et al. A comparison of ventilation/perfusion single photon emission CT and $\mathrm{CT}$ pulmonary angiography for diagnosis of pulmonary embolism. Zhonghua Jie He He Hu Xi Za Zhi. 2013;36:177-81.

141. Leuschner G, Wenter V, Milger K, Zimmermann GS, Matthes S, Meinel FG, et al. Suspected pulmonary embolism in patients with pulmonary fibrosis: discordance between ventilation/perfusion SPECT and CT pulmonary angiography. Respirology. 2016;21: 1081-7. https://doi.org/10.1111/resp.12797.

142. Gopalan D, Delcroix M, Held M. Diagnosis of chronic thromboembolic pulmonary hypertension. Eur Respir Rev. 2017;26. https://doi.org/10.1183/16000617.0108-2016.

143. Sabarudin A, Mustafa Z, Nassir KM, Hamid HA, Sun Z. Radiation dose reduction in thoracic and abdomen-pelvic CT using tube current modulation: a phantom study. J Appl Clin Med Phys. 2014;16:5135. https://doi.org/10.1120/jacmp.v16i1. 5135.

144. Revel MP, Fitton I, Audureau E, Benzakoun J, Lederlin M, Chabi $\mathrm{ML}$, et al. Breast dose reduction options during thoracic CT: influence of breast thickness. AJR Am J Roentgenol. 2015;204: W421-8. https://doi.org/10.2214/AJR.14.13255. 
145. Grüning T, Mingo RE, Gosling MG, Farrell SL, Drake BE, Loader $\mathrm{RJ}$, et al. Diagnosing venous thromboembolism in pregnancy. Br J Radiol. 2016;89:20160021. https://doi.org/10.1259/bjr.20160021.

146. Begic A, Opankovic E, Cukic V, Lindqvist A, Miniati M, Bajc M. Ancillary findings assessed by ventilation/perfusion tomography. Impact and clinical outcome in patients with suspected pulmonary embolism. Nuklearmedizin. 2015;54:223-30. https://doi.org/10. 3413/Nukmed-0748-15-06.

147. Bajc M, Olsson B, Gottsäter A, Hindorf C, Jögi J. V/P SPECT as a diagnostic tool for pregnant women with suspected pulmonary embolism. Eur J Nucl Med Mol Imaging. 2015;42:1325-30. https://doi.org/10.1007/s00259-015-3056-z.

148. Jobse BN, Rhem RG, McCurry CA, Wang IQ, Labiris NR. Imaging lung function in mice using SPECT/CT and per-voxel analysis. PLoS One. 2012;7:e42187. https://doi.org/10.1371/ journal.pone.0042187.

149. Norberg P, Persson HL, Schmekel B, Carlsson GA, Wahlin K, Sandborg M, et al. Does quantitative lung SPECT detect lung abnormalities earlier than lung function tests? Results of a pilot study. EJNMMI Res. 2014;4:39. https://doi.org/10.1186/s13550014-0039-1.

150. Friedman WF, Braunwald E. Alterations in regional pulmonary blood flow in mitral valve disease studied by radioisotope scanning. A simple nontraumatic technique for estimation of left atrial pressure. Circulation. 1966;34:363-76.

151. Jögi J, Palmer J, Jonson B, Bajc M. Heart failure diagnostics based on ventilation/perfusion single photon emission computed tomography pattern and quantitative perfusion gradients. Nucl Med Commun. 2008;29:666-73. https://doi.org/10.1097/MNM. 0b013e328302cd26.

152. Pistolesi M, Miniati M, Bonsignore M, Andreotti F, Di Ricco G, Marini C, et al. Factors affecting regional pulmonary blood flow in chronic ischemic heart disease. J Thorac Imaging. 1988;3:65-72.

153. Jögi J, Al-Mashat M, Rådegran G, Bajc M, Arheden H. Diagnosing and grading heart failure with tomographic perfusion lung scintigraphy: validation with right heart catheterization. ESC Heart Fail. 2018. https://doi.org/10.1002/ehf2.12317.

154. Ewig S, Birkner N, Strauss R, Schaefer E, Pauletzki J, Bischoff H, et al. New perspectives on community-acquired pneumonia in 388 406 patients. Results from a nationwide mandatory performance measurement programme in healthcare quality. Thorax. 2009;64: 1062-9. https://doi.org/10.1136/thx.2008.109785.

155. Carvalho P, Lavender JP. The incidence and etiology of the ventilation/perfusion reverse mismatch defect. Clin Nucl Med. 1989;14:571-6.

156. Li DJ, Stewart I, Miles KA, Wraight EP. Scintigraphic appearances in patients with pulmonary infection and lung scintigrams of intermediate or low probability for pulmonary embolism. Clin Nucl Med. 1994;19:1091-3.

157. Sostman HD, Gottschalk A. Prospective validation of the stripe sign in ventilation-perfusion scintigraphy. Radiology. 1992;184: 455-9. https://doi.org/10.1148/radiology.184.2.1620847.

158. Sostman HD, Ravin CE, Sullivan DC, Mills SR, Glickman MG, Dorfman GS. Use of pulmonary angiography for suspected pulmonary embolism: influence of scintigraphic diagnosis. AJR Am J Roentgenol. 1982;139:673-7. https://doi.org/10.2214/ajr.139.4. 673.

159. Hofman MS, Callahan J, Eu P, Hicks RJ. Segmental hyperperfusion in lobar pneumonia visualized with respiratory-gated fourdimensional pulmonary perfusion positron emission tomography-computed tomography. Am J Respir Crit Care Med. 2014;189:104-5. https://doi.org/10.1164/rccm.201307-1196IM.

160. Bajc M. Value of ventilation/perfusion SPECT detecting extensive pulmonary embolism in a patient with pneumonia. Thromb Haemost. 2005;93:993-4.
161. Guérin L, Couturaud F, Parent F, Revel MP, Gillaizeau F, Planquette B, et al. Prevalence of chronic thromboembolic pulmonary hypertension after acute pulmonary embolism. Prevalence of CTEPH after pulmonary embolism. Thromb Haemost. 2014;112:598-605. https://doi.org/10.1160/th13-070538.

162. Kayaalp I, Varol Y, Çimen P, Demirci Üçsular F, Katgi N, Ünlü M, et al. The incidence of chronic thromboembolic pulmonary hypertension secondary to acute pulmonary thromboembolism. Tuberk Toraks. 2014;62:199-206.

163. Lang IM, Pesavento R, Bonderman D, Yuan JX. Risk factors and basic mechanisms of chronic thromboembolic pulmonary hypertension: a current understanding. Eur Respir J. 2013;41:462-8. https://doi.org/10.1183/09031936.00049312.

164. Tunariu N, Gibbs SJ, Win Z, Gin-Sing W, Graham A, Gishen P, et al. Ventilation-perfusion scintigraphy is more sensitive than multidetector CTPA in detecting chronic thromboembolic pulmonary disease as a treatable cause of pulmonary hypertension. $\mathrm{J}$ Nucl Med. 2007;48:680-4. https://doi.org/10.2967/jnumed.106. 039438.

165. Soler X, Kerr KM, Marsh JJ, Renner JW, Hoh CK, Test VJ, et al. Pilot study comparing SPECT perfusion scintigraphy with CT pulmonary angiography in chronic thromboembolic pulmonary hypertension. Respirology. 2012;17:180-4. https://doi.org/10. 1111/j.1440-1843.2011.02061.x.

166. Dournes G, Verdier D, Montaudon M, Bullier E, Rivière A, Dromer C, et al. Dual-energy CT perfusion and angiography in chronic thromboembolic pulmonary hypertension: diagnostic accuracy and concordance with radionuclide scintigraphy. Eur Radiol. 2014;24:42-51. https://doi.org/10.1007/s00330-0132975-y.

167. Kim NH, Delcroix M, Jenkins DP, Channick R, Dartevelle P, Jansa $\mathrm{P}$, et al. Chronic thromboembolic pulmonary hypertension. J Am Coll Cardiol. 2013;62:D92-9. https://doi.org/10.1016/j.jacc. 2013.10.024.

168. Klok FA, Delcroix M, Bogaard HJ. Chronic thromboembolic pulmonary hypertension from the perspective of patients with pulmonary embolism. J Thromb Haemost. 2018;16:1040-51. https://doi. org/10.1111/jth.14016.

169. Stricker H. Chronic thromboembolic pulmonary hypertension-a diagnostic and therapeutic update. Vasa. 2016;45:195-9. https:// doi.org/10.1024/0301-1526/a000525.

170. Eslick EM, Stevens MJ, Bailey DL. SPECT V/Q in lung cancer radiotherapy planning. Semin Nucl Med. 2019;49:31-6. https:// doi.org/10.1053/j.semnuclmed.2018.10.009.

171. Gray G, Nelson-Piercy C. Thromboembolic disorders in obstetrics. Best Pract Res Clin Obstet Gynaecol. 2012;26:53-64. https:// doi.org/10.1016/j.bpobgyn.2011.10.003.

172. Bourjeily G, Paidas M, Khalil H, Rosene-Montella K, Rodger M. Pulmonary embolism in pregnancy. Lancet. 2010;375:500-12. https://doi.org/10.1016/S0140-6736(09)60996-X.

173. Kline JA, Richardson DM, Than MP, Penaloza A, Roy PM. Systematic review and meta-analysis of pregnant patients investigated for suspected pulmonary embolism in the emergency department. Acad Emerg Med. 2014;21:949-59. https://doi.org/10. 1111/acem.12471.

174. Sivandarajah S. Towards evidence-based emergency medicine: best BETs from the Manchester Royal Infirmary. BET 4: current evidence does not support the use of a negative D-dimer to rule out suspected pulmonary embolism in pregnancy. Emerg Med J. 2011;28:245-6. https://doi.org/10.1136/emj.2011.111617.

175. Bourjeily G, Khalil H, Raker C, Martin S, Auger P, Chalhoub M, et al. Outcomes of negative multidetector computed tomography with pulmonary angiography in pregnant women suspected of pulmonary embolism. Lung. 2012;190:105-11. https://doi.org/ 10.1007/s00408-011-9329-9. 
176. Cahill AG, Stout MJ, Macones GA, Bhalla S. Diagnosing pulmonary embolism in pregnancy using computed-tomographic angiography or ventilation-perfusion. Obstet Gynecol. 2009;114:1249. https://doi.org/10.1097/AOG.0b013e3181a99def.

177. Leung AN, Bull TM, Jaeschke R, Lockwood CJ, Boiselle PM, Hurwitz LM, et al. An official American Thoracic Society/Society of Thoracic Radiology clinical practice guideline: evaluation of suspected pulmonary embolism in pregnancy. Am J Respir Crit Care Med. 2011;184:1200-8. https://doi.org/10.1164/rccm. 201108-1575ST.

178. Ridge CA, McDermott S, Freyne BJ, Brennan DJ, Collins CD, Skehan SJ. Pulmonary embolism in pregnancy: comparison of pulmonary CT angiography and lung scintigraphy. AJR Am J Roentgenol. 2009;193:1223-7. https://doi.org/10.2214/AJR.09. 2360.

179. U-King-Im JM, Freeman SJ, Boylan T, Cheow HK. Quality of CT pulmonary angiography for suspected pulmonary embolus in pregnancy. Eur Radiol. 2008;18:2709-15. https://doi.org/10. 1007/s00330-008-1100-0.

180. Hurwitz LM, Yoshizumi T, Reiman RE, Goodman PC, Paulson EK, Frush DP, et al. Radiation dose to the fetus from body MDCT during early gestation. AJR Am J Roentgenol. 2006;186:871-6. https://doi.org/10.2214/ajr.04.1915.

181. Ridge CA, Mhuircheartaigh JN, Dodd JD, Skehan SJ. Pulmonary CT angiography protocol adapted to the hemodynamic effects of pregnancy. AJR Am J Roentgenol. 2011;197:1058-63. https://doi. org/10.2214/AJR.10.5385.

182. Cogley JR, Ghobrial PM, Chandrasekaran B, Allen SB. Pulmonary embolism evaluation in the pregnant patient: a review of current imaging approaches. Semin Ultrasound CT MR. 2012;33:11-7. https://doi.org/10.1053/j.sult.2011.09.001.

183. Revel MP, Cohen S, Sanchez O, Collignon MA, Thiam R, Redheuil A, et al. Pulmonary embolism during pregnancy: diagnosis with lung scintigraphy or CT angiography? Radiology. 2011;258:590-8. https://doi.org/10.1148/radiol.10100986.

184. Shahir K, Goodman LR, Tali A, Thorsen KM, Hellman RS. Pulmonary embolism in pregnancy: CT pulmonary angiography versus perfusion scanning. AJR Am J Roentgenol. 2010;195: W214-20. https://doi.org/10.2214/AJR.09.3506.

185. Chauvet P, Terral D, Colombier M, Mulliez A, Suarez C, Brunhes $\mathrm{A}$, et al. Iodinated contrast in pregnant women and neonatal thyroid function. Gynecol Obstet Fertil. 2016;44:685-9. https:// doi.org/10.1016/j.gyobfe.2016.09.011.

186. Scarsbrook AF, Bradley KM, Gleeson FV. Perfusion scintigraphy: diagnostic utility in pregnant women with suspected pulmonary embolic disease. Eur Radiol. 2007;17:2554-60. https://doi.org/10. 1007/s00330-007-0607-0.

187. Nijkeuter M, Geleijns J, De Roos A, Meinders AE, Huisman MV. Diagnosing pulmonary embolism in pregnancy: rationalizing fetal radiation exposure in radiological procedures. $\mathrm{J}$ Thromb Haemost. 2004;2:1857-8. https://doi.org/10.1111/j.1538-7836.2004.00929. $\mathrm{x}$.

188. Perisinakis K, Seimenis I, Tzedakis A, Damilakis J. Perfusion scintigraphy versus 256 -slice CT angiography in pregnant patients suspected of pulmonary embolism: comparison of radiation risks. J Nucl Med. 2014;55:1273-80. https://doi.org/10.2967/jnumed. 114.137968

189. Woussen S, Lopez-Rendon X, Vanbeckevoort D, Bosmans H, Oyen R, Zanca F. Clinical indications and radiation doses to the conceptus associated with CT imaging in pregnancy: a retrospective study. Eur Radiol. 2016;26:979-85. https://doi.org/10.1007/ s00330-015-3924-8.

190. Cook JV, Kyriou J. Radiation from CT and perfusion scanning in pregnancy. BMJ. 2005;331:350. https://doi.org/10.1136/bmj.331. 7512.350 .

191. Elbakri IA. Estimation of dose-area product-to-effective dose conversion factors for neonatal radiography using PCXMC. Radiat Prot Dosim. 2014;158:43-50. https://doi.org/10.1093/rpd/nct192.

192. Homolka P, Leithner R, Billinger J, Gruber M. Results of the Austrian CT dose study 2010: typical effective doses of the most frequent CT examinations. Z Med Phys. 2014;24:224-30. https:// doi.org/10.1016/j.zemedi.2013.12.005.

193. Leung AN, Bull TM, Jaeschke R, Lockwood CJ, Boiselle PM, Hurwitz LM, et al. American Thoracic Society documents: an official American Thoracic Society/Society of Thoracic Radiology Clinical Practice Guideline-evaluation of suspected pulmonary embolism in pregnancy. Radiology. 2012;262:63546. https://doi.org/10.1148/radiol.11114045.

Publisher's note Springer Nature remains neutral with regard to jurisdictional claims in published maps and institutional affiliations. 